1

2

3

4

5

\title{
Hierarchical assembly of the MLL1 core complex within a biomolecular condensate regulates H3K4 methylation
}

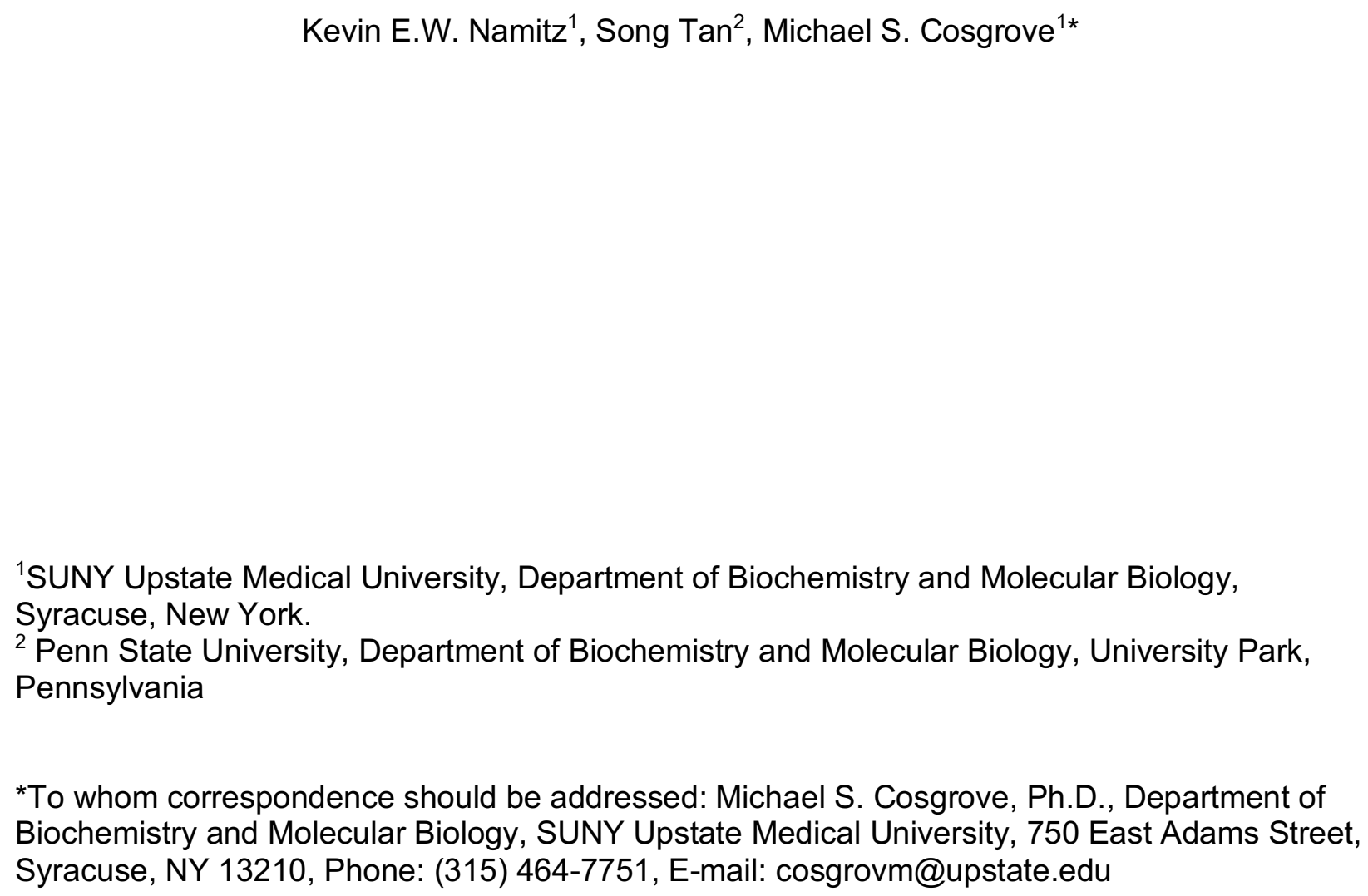

*To whom correspondence should be addressed: Michael S. Cosgrove, Ph.D., Department of Biochemistry and Molecular Biology, SUNY Upstate Medical University, 750 East Adams Street, Syracuse, NY 13210, Phone: (315) 464-7751, E-mail: cosgrovm@upstate.edu 


\section{ABSTRACT}

The enzymes that regulate histone $\mathrm{H} 3$ lysine 4 (H3K4) methylation are required for

42 cellular differentiation and development and are often mutated in human disease. Mixed

43 Lineage Leukemia protein-1 (MLL1) is a member of the SET1 family of histone H3 lysine 4

44 methyltransferases, which require interaction with a conserved sub-complex consisting of

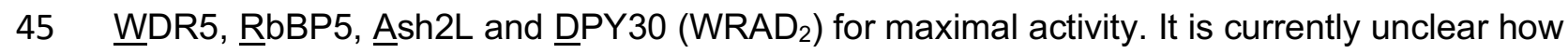

46 assembly of SET1 family complexes is involved in the spatiotemporal control of H3K4

47 methylation in eukaryotic genomes. In this investigation, we systematically characterized the

48 hydrodynamic and kinetic properties of a reconstituted human MLL1 core complex and found

49 that its assembly is highly concentration and temperature dependent. Consistent with a

50 hierarchical assembly pathway, we found that the holo-complex assembles through interactions

51 between the MW and $\mathrm{RAD}_{2}$ sub-complexes, which is correlated with enzymatic activity.

52 Surprisingly, we found that the disassembled state is favored at physiological temperatures, and

53 that this thermodynamic barrier can be overcome under conditions that induce high-local

54 concentrations of subunits in phase separated compartments. Combining this data with the

55 observation that MLL1 primary sequence contains large regions of intrinsic disorder, we

56 propose a "swinging-domain" model in which the interaction between a tethered MW

57 subcomplex and multiple nucleosome-RAD 2 complexes is regulated by the rapid formation or

58 dissolution of biomolecular condensates, such as occurs in transcription factories. This model

59 provides an elegant "switch-like" mechanism for spatiotemporal control of H3K4 methylation

60 within eukaryotic genomes. 


\section{INTRODUCTION}

Cellular identity in multicellular organisms is maintained in part by enzymes that regulate the degree of histone $\mathrm{H} 3$ lysine $4(\mathrm{H} 3 \mathrm{~K} 4)$ methylation (1). Di- and trimethylation of $\mathrm{H} 3 \mathrm{~K} 4$ $(\mathrm{H} 3 \mathrm{~K} 4 \mathrm{me} 2,3)$ are enriched in gene bodies and promoters of active genes (2-4) respectively, and function to recruit nucleosome-remodeling complexes that regulate transcription (5-9). H3K4 monomethylation ( $\mathrm{H} 3 \mathrm{~K} 4 \mathrm{me} 1$ ) is associated with active gene enhancers (10-12), but is also associated with gene silencing (13-17). Because genome-wide alterations in the patterns of $\mathrm{H} 3 \mathrm{~K} 4$ methylation are linked to the aberrant transcriptional programs in developmental disorders and cancers (18-28), there is significant interest in understanding how different H3K4 methylation states are established and maintained.

Mixed Lineage Leukemia protein-1 (MLL1, ALL1, HRX, KMT2C) is a member of the SET1 family of H3K4 methyltransferases and is frequently altered in poor prognosis acute leukemias (29). MLL1 is a large protein with 3,969 amino acids and assembles into a supercomplex with $\sim 30$ subunits (30-33). Subunits shared among all SET1 family members include

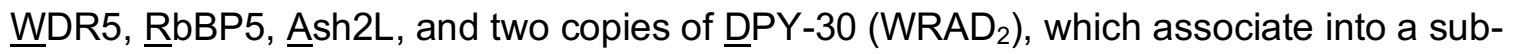
complex that interacts with the C-terminal SuVar, Ez, Trx (SET) domain of MLL1 (34-38). In vitro studies have shown that the MLL1 SET domain predominantly catalyzes H3K4 monomethylation (36), whereas multiple methylation depends on interaction of MLL1 with $W_{R A D}$, forming what is known as the MLL1 core complex (also known as human COMPASS, or $\left.M W R A D_{2}\right)(34,36,39)$. The requirement of full $M W R A D_{2}$ complex for optimal enzymatic activity suggests that $\mathrm{H} 3 \mathrm{~K} 4$ methylation may be regulated at the level of subunit assembly in the cell. Consistent with this hypothesis, genome-wide studies show that, while MLL1 localizes to thousands of genes in mammalian genomes, multiple methylation of H3K4 is mainly correlated with the subset of genes where MLL1 co-localizes with $\mathrm{WRAD}_{2}$ subunits (40). In addition, disease-specific missense mutations have been shown to disrupt MLL family core complexes (41), suggesting that aberrations in complex assembly may be associated with human disease.

87 More recently, several labs have shown that perturbation of MLL1 core complex assembly with

88 protein-protein interaction inhibitors may have utility as a novel therapeutic approach for treating 89 malignancies (42-44). Together, these results suggest that knowledge of the molecular 90 mechanisms controlling MLL1 core complex assembly will be crucial for understanding of how 91 different H3K4 methylation states are regulated in mammalian genomes. However, progress

92 has been impeded by the lack of understanding of the biophysical and thermodynamic

93 mechanisms that underlie MLL1 core complex assembly. 
Biochemical reconstitution studies using a minimal MLL1 SET domain construct show that the stoichiometry of the MLL1 core complex consists of one copy of the MLL1, WDR5, RbBP5 and Ash2L subunits, and 2 copies of the DPY-30 subunit (MWRAD $)$ - forming a complex with a mass of $\sim 205 \mathrm{kDa}$ (36). Direct interactions have been observed between MLL1 and WDR5 $(35,37,45)$, WDR5 and RbBP5 $(46,47)$, RbBP5 and Ash2L (36), and Ash2L and DPY30 $(36,48,49)$. While these pairwise interactions suggest a linear arrangement of subunits, several lines of evidence indicate a more intricate quaternary structure. For example, while MLL1 does not interact with RbBP5 or Ash2L in pairwise experiments (36), an investigation of SET domainassociated Kabuki syndrome missense mutations suggests a direct interaction with the $\mathrm{RbBP5/Ash} 2 \mathrm{~L}$ heterodimer within the context of the holo-complex (41). The WDR5 subunit functions to stabilize this interaction by directly binding to the MLL1 WDR5 interaction (Win) motif $(35,37,45)$ and RbBP5 $(34,36)$. Binding experiments show that the weakest pairwise interaction occurs between the WDR5 and RbBP5 subunits (36), suggesting the complex may be hierarchically assembled. All of these interactions have been confirmed in recent Cryo-EM and X-ray crystal structures of related SET1 family complexes (50-53). Together, these results suggest that complex assembly is hierarchical in nature, with the requirement for the formation of distinct sub-complexes before assembly of the higher-order quaternary structure. The choreographic details of this assembly pathway are unknown.

In this investigation, we systematically characterized the hydrodynamic and kinetic properties of a reconstituted human MLL1 core complex under a variety of conditions. We found that MLL1 core complex assembly is highly concentration and temperature dependent. Consistent with the hypothesized hierarchical assembly pathway, we found that the holocomplex assembles through interactions between the MW and $\mathrm{RAD}_{2}$ sub-complexes, and that $M W R A D_{2}$ formation is directly correlated with enzymatic activity. Surprisingly, we found that the disassembled state is favored at physiological temperatures and at concentrations typically used in steady-state enzymatic assays. In contrast, sub-physiological ionic strength dramatically increases enzymatic activity, which is associated with the formation of induced high-local

121 concentrations of the MLL1 core complex in phase-separated droplets. Based on these results,

122 we propose a model in which the thermodynamic barrier to complex assembly is overcome in

123 the cell under conditions that induce high-local concentrations of subunits, such as those found

124 in transcription factories. Together, these results are consistent with the hypothesis that

125 regulated assembly of the MLL1 core complex underlies an important mechanism for

126 establishing different $\mathrm{H} 3 \mathrm{~K} 4$ methylation states in mammalian genomes. 


\section{RESULTS}

\section{MLL1 core complex assembly is concentration and temperature dependent}

To better understand MLL1 core complex assembly, we purified human recombinant $\mathrm{MWRAD}_{2}$ as described in Methods and characterized its oligomeric behavior by size exclusion

132 chromatography (SEC) and sedimentation velocity analytical ultracentrifugation (SV-AUC). SEC 133 revealed that the purified complex eluted as a single symmetrical peak (Fig. 1A) and SDS-

134 PAGE of the indicated fractions showed the presence of all five subunits with the expected 135 stoichiometry (Fig. 1B). We note that the complex elutes later than expected based on its 136 theoretical mass, which is likely due to the significant shape asymmetry of the particle. We then 137 chose SV-AUC to characterize the concentration and temperature dependence of the complex 138 in solution. SV-AUC is a first-principle technique that measures the time course of sedimentation of macromolecules in a gravitational field in a way that maintains the equilibrium of reversible associations - allowing extraction of equilibrium and kinetic properties of interactions $(54,55)$. Sedimentation boundaries formed as the particle sediments over time were

142 fit using a finite element analysis of Lamm equation solutions (Fig. 1C) (56) to give the diffusion-

143 free sedimentation coefficient distribution $c(s)$ (Fig. 1D). The $c(s)$ plot of $\mathrm{MWRAD}_{2}$ at $5 \mu \mathrm{M}$

144 loading concentration at $5^{\circ} \mathrm{C}$ revealed a large peak accounting for almost $90 \%$ of the signal with 145 an $S_{20, w}(S)$ value of 7.2 and two minor peaks at 2.9 and $4.7 S$ that each account for $4-5 \%$ of the 146 signal (noted with arrows in Fig. 1D). The major peak at $7.2 S$ corresponds to the fully

147 assembled MLL1 core complex, which we previously showed assembles with a stoichiometry of $148 \quad 1: 1: 1: 1: 2$ for the MWRAD 2 subunits, respectively (36). In addition, the $S$-value of $M W R A D_{2}$ is 149 independent of loading concentration (Fig. 2A), indicating that the complex is stable at $5^{\circ} \mathrm{C}$ and 150 has a relatively long lifetime compared to the timescale of sedimentation (57). Using the derived weight-averaged frictional coefficient $\left(f / f_{0}\right)$ of 1.7 , the calculated molecular mass from this $S$ value was 209,561 Daltons, which is within error of the expected mass $(205,402)$ based on the amino acid sequence of the holo-complex subunits at the indicated stoichiometry.

The minor peaks observed in the $c(s)$ distribution in Fig. 1D could represent trace contaminants in the sample or minor populations of dissociated sub-complexes and/or subunits. To distinguish these hypotheses, we compared $c(s)$ distributions of $M W R A D_{2}$ at concentrations 157 ranging from $0.25-5 \mu \mathrm{M}$ at $5^{\circ} \mathrm{C}$ (Fig. 2A) and $30^{\circ} \mathrm{C}$ (Fig. 2B). If the minor peaks represent non158 interacting contaminants, then the relative amount of signal between the major and minor peaks 159 will not vary as the loading concentration is decreased. In contrast, if the complex is dissociating 160 into sub-complexes, then the relative amount of signal in the major and minor peaks will change 161 as the loading concentration is varied. The results were consistent with the latter possibility. For 
example, while the effect at $5^{\circ} \mathrm{C}$ was modest, when the loading concentration of the complex was decreased from $5 \mu \mathrm{M}$ to $0.25 \mu \mathrm{M}$, the amount of signal corresponding to the holo-complex decreased from $\sim 88 \%$ to $\sim 83 \%$ of the total signal, with a corresponding increase in both minor peak signals (Fig. 2A). The effect was more obvious at $30^{\circ} \mathrm{C}$, which showed that the signal corresponding to the minor peaks increased from $35 \%$ to $75 \%$ of the total signal as the loading concentration was decreased (Fig. 2B). These results suggest that the minor peaks represent dissociated sub-complexes and/or subunits. Furthermore, because the $S$-values of the minor peaks show varying degrees of concentration dependence, they likely represent reaction boundaries of sub-complexes as opposed to individual non-interacting subunits. These data suggest that the holo-complex assembles from predominantly two sub-complexes in a temperature and concentration-dependent manner.

\section{The disassembled state of the MLL1 core complex is favored at physiological temperature}

To further explore the thermodynamics of MLL1 core complex assembly, we compared the temperature dependence of $\mathrm{MWRAD}_{2}$ formation at several different loading concentrations using SV-AUC (Fig. 3). Each $c(s)$ profile was integrated and the relative amount of signal corresponding to the $S$ value of the holo-complex was plotted as a function of temperature and total loading concentration (Fig. 3F). At the highest loading concentration ( $5 \mu \mathrm{M})$, little variation in the amount of holo-complex was observed between $5^{\circ}$ and $25^{\circ} \mathrm{C}$ (Fig. 3A, F), with a peak that accounted for $81-92 \%$ of the total signal (Table S1). In contrast, at temperatures greater than $25^{\circ} \mathrm{C}$, the amount of holo-complex decreased precipitously until only $\sim 3 \%$ of the signal could be observed at $37^{\circ} \mathrm{C}$ (Figs. 3A and F, Table S1). The effect of temperature on MLL1 core complex stability became increasingly more severe as the loading concentration was decreased. For example, at the lowest loading concentration $(0.25 \mu \mathrm{M})$, only the $5^{\circ} \mathrm{C}$ and $10^{\circ} \mathrm{C}$ runs showed $\sim 80 \%$ holo-complex (Fig. 3E, F; Table S1); whereas at higher temperatures, the signal corresponding to the holo-complex decreased from $\sim 63 \%$ at $15^{\circ} \mathrm{C}$ - to $\sim 2 \%$ of the total signal at $37^{\circ} \mathrm{C}$ (Fig. 3F; Table S1). At $37^{\circ} \mathrm{C}$, most of the signal is instead dominated by the two subcomplex peaks with S-values of $\sim 3$ and 4.7 (Fig. 3G). These data are consistent with the hypothesis that the holo-MLL1 core complex assembles from interaction of two sub-complexes, the equilibrium of which is highly concentration and temperature-dependent.

Surprisingly, at all the concentrations tested, very little holo-complex with an $S$ value of 7.2 was observed at physiological temperature $\left(37^{\circ} \mathrm{C}\right)($ Fig. $3 \mathrm{G})$. This suggests that the 
disassembled state of the MLL1 core complex may predominate in cells, and that other factors are required to stabilize the assembled state. In support of this hypothesis, closer examination of the $c(s)$ profiles of the complex at $37^{\circ} \mathrm{C}$ revealed evidence that increased protein concentration promotes complex formation. For example, while similar amounts of signal are observed in the two sub-complex peaks at the $0.25 \mu \mathrm{M}$ loading concentration (cyan line, Fig. $3 G$ ), the relative amount of signal in the two peaks changes with progressively higher concentrations. The intensity of the larger peak increased at the expense of the smaller peak and began to show evidence of concentration-dependent shifting to higher $S$-values. This hydrodynamic behavior is consistent with a reaction boundary composed of free and bound reactants that interconvert under a rapid kinetic regime that cannot be resolved within the signal-to-noise of the experiment (57). These results suggest that, unlike the long lifetime of the assembled complex observed at $5^{\circ} \mathrm{C}$, the kinetics of the interaction have changed at $37^{\circ} \mathrm{C}$ such that the complex now has a short lifetime compared to the timescale of sedimentation.

We next analyzed the concentration series at each temperature to derive binding isotherms. We integrated each $c(s)$ profile (between 0.5 and $9.5 S$ ) to determine the weightaverage sedimentation coefficients $\left(s_{w}\right)(58)$, which were then plotted against $\mathrm{MWRAD}_{2}$ concentration and fit to derive the apparent dissociation constant $\left(K_{d}^{a p p}\right)$ for each isotherm (Fig. $4 \mathrm{~A})$. Given that the majority of signal in each $c(s)$ profile could be assigned to three peaks, we applied the $A+B \leftrightarrows A B$ hetero-association model in the program SEDPHAT (59) and obtained reasonable fits (Table 1). The derived $K_{d}{ }^{\text {app }}$ values ranged from $7 \mathrm{nM}$ at $5^{\circ} \mathrm{C}$ to $\sim 6,200 \mathrm{nM}$ at $37^{\circ} \mathrm{C}$ (Table 1). A van't Hoff analysis showed that complex formation is exothermic, which is offset by the negative entropy change as the complex subunits become more ordered (Fig. 4B and $\mathrm{C}$ ). However, the van't Hoff plot reveals a non-linear relationship between $\mathrm{K}_{\text {eq }}$ and temperature, indicating a change in the heat capacity of the system at higher temperatures (Fig. 4B). These data suggest at least two mechanisms for complex assembly, which differ by

221 relatively long lifetime that is stable on the timescale of sedimentation. Under this mechanism,

222 the interaction is dominated by enthalpic contributions to the free energy (Fig. 4C). At high

223 temperatures $\left(>25^{\circ} \mathrm{C}\right)$, the equilibrium is shifted into the rapid kinetic regime with a short

224 complex lifetime where dissociation is more likely. While there is little difference in the Gibbs

225 free energy between mechanisms, there is a difference in the contributions between the

226 enthalpic and entropic terms. At higher temperatures, the entropic penalty to complex formation

227 was increased 7-fold compared to that of the lower temperature mechanism, while the 
difference in the enthalpic contribution was only increased by 3.8-fold (Fig. 4C). These results suggest that, at physiological temperature, one or more of the subunits samples alternate conformational states, some of which are not competent for complex assembly. However, given the observation that some holo-complex forms in a concentration-dependent manner, increased

232 local concentration of subunits may be a mechanism that cells use to overcome the increased 233 entropic cost of complex formation at $37^{\circ} \mathrm{C}$.

The MLL1 core complex assembles from $M W$ and $R A D_{2}$ sub-complexes interactions as follows: $M \rightleftharpoons W \rightleftharpoons R \rightleftharpoons A \rightleftharpoons D_{2}$ (36). Since the weakest pairwise interaction occurs between WDR5 and RbBP5 (36), we predicted that the complex assembles by first forming $\mathrm{MW}$ and $\mathrm{RAD}_{2}$ sub-complexes, which then interact to form the holo-complex (Scheme 1). However, we reasoned that there are at least two additional reaction schemes that could potentially give rise to the three boundaries observed in the holo-complex $c(s)$ profiles

242 (Schemes 2 and 3). To distinguish among these schemes, we chose to use a Bayesian

243 approach to analyze the SV-AUC data of the holo-complex collected at $25^{\circ} \mathrm{C}$. The Bayesian

244 approach is a variant of the standard maximum entropy regularization method utilized in the $c(s)$ 245 analysis in that, instead of assuming a uniform probability for the occurrence of species at every $246 S$-value in a distribution, it utilizes prior information to assign different probabilities in different 247 regions of S-values (60). A key feature of the Bayesian implementation in SEDFIT is that,

248 because it maintains the same degrees of freedom used in the standard $c(s)$ analysis,

249 imperfections in the expected values will result in additional features in the $c^{(p)}(s)$ plots in order

250 to maintain the quality of the fit (60). The Bayesian analysis therefore allows us to determine 251 which reaction scheme gives a $c^{(p)}(s)$ profile that best fits the experimental data.

Scheme 2: $\quad M+W \rightleftharpoons M W+R \rightleftharpoons M W R+A D_{2} \rightleftharpoons M W R A D_{2}$

Scheme 3: $\quad W+R \rightleftharpoons W R+A D_{2} \rightleftharpoons W R A D_{2}+M \rightleftharpoons M W R A D_{2}$

To obtain the expected S-values for each of the predicted sub-complexes or subunits in each reaction scheme, we mixed stoichiometric amounts of their respective subunits and characterized their concentration dependence by SV-AUC at $25^{\circ} \mathrm{C}$ (Fig. S1; Table S2). We then 
used each of the $S$-values collected at $0.25 \mu \mathrm{M}$ as prior expectations in the Bayesian analysis of

263 the holo-complex. As shown in Fig. 5A, when the independently determined S-values for MW,

$264 \mathrm{RAD}_{2}$ and the $M W R A D_{2}$ species were used as prior expectations in the Bayesian analysis of the

265 holo-complex at $0.25 \mu \mathrm{M}$ (black dotted line), three peaks in the $c^{(p)}(s)$ plot were observed that

266 were in excellent agreement with the expectations (cyan line). Indeed, good agreement was

267 observed using the same $S$-values as prior expectations for Bayesian fits of the experimental

268 data collected at higher holo-complex concentrations (Fig. 5A). The only deviation observed

269 was for the position and amplitude of the holo-complex peak, which at $25^{\circ} \mathrm{C}$ shifts from 6.8 to

$2707.2 S$ in a concentration-dependent manner (Fig. 5A). In contrast, when a similar analysis was

271 conducted instead using the expected $S$-values for the MWR and $A D_{2}$ sub-complexes predicted

272 by Scheme 2, additional features in the $c^{(p)}(s)$ plot with an $S$-value of $\sim 5.3$ were observed at all

273 loading concentrations that did not match the prior expectations (Fig. 5B, red arrow). Similarly,

274 using the expected $S$-values for $M$ and $\mathrm{WRAD}_{2}$ as predicted by Scheme 3 , the $c^{(p)}(s)$ plot

275 showed little evidence of a species matching the expected value of free MLL1 at 2.3 S, and also

276 showed additional features at $\sim 3.5$ Sthat did not match expectations (Fig. 5C, red arrow). To

277 test whether the holo-complex assembles in a concerted fashion from individual subunits, we

278 also performed a similar Bayesian analysis using the predetermined $S$ values for $M, W, R, A D_{2}$,

279 and $M W R A D_{2}$ as prior expectations $\left(A D_{2}\right.$ is treated as a discrete species since it does not

280 appreciably dissociate under the range of concentrations that can be detected by the

281 absorbance optical system used in these experiments (36)). The $c^{(p)}(s)$ plot showed additional

282 features with an $S$-value of $\sim 5.2$ that did not match expectations (Fig. 5D, red arrow). Together,

283 these results are consistent with the hypothesis that MLL1 core complex is hierarchically

284 assembled by association of $\mathrm{MW}$ and $\mathrm{RAD}_{2}$ sub-complexes.

Enzymatic activity of the MLL1 core complex is directly related to complex assembly

To determine the impact of concentration and temperature on the enzymatic activity of

288 the MLL1 core complex, we incubated $\mathrm{MWRAD}_{2}(0.25-5 \mu \mathrm{M})$ with a fixed concentration of

289 histone $\mathrm{H} 3$ peptide $(10 \mu \mathrm{M})$ and saturating amounts of AdoMet $(250 \mu \mathrm{M})$ at various

290 temperatures. We then measured methylation using a label-free quantitative MALDI-TOF mass

291 spectrometry assay (36). MALDI spectra were integrated and the relative amount of each

292 peptide species was plotted as a function of time. Data were fit using a numerical integration of

293 rate equations approach implemented in KinTek Explorer software (61), which allowed us to test

294 the ability of different reaction schemes to fit the data. 
Using the simplest irreversible consecutive reactions model (Fig. 6, Scheme 4), while acceptable fits were obtained for reaction progress curves collected at the highest concentration

$297(5 \mu \mathrm{M})$ between temperatures $5-30^{\circ} \mathrm{C}\left(5^{\circ} \mathrm{C}\right.$ is shown in Fig. $\left.6 \mathrm{~A}\right)$, the rest of the fits were poor 298 (an example is shown in Fig. 6B). Since we previously showed that the complex uses a non299 processive mechanism for multiple lysine methylation (36), we revised the model to incorporate 300 binding of peptide substrate to the enzyme-AdoMet complex $\left(E_{1}\right)$ and release of the H3K4me1 301 product after the first methylation event, followed by binding of the H3K4me1 substrate to a 302 distinct site on the enzyme $\left(E_{2}\right)$ for the dimethylation reaction. The latter step is predicated on 303 our previous observation that the MLL1 core complex has a cryptic second active-site 304 independent of the SET domain that is required for the H3K4 dimethylation reaction $(36,62,63)$. 305 Since the binding and release rates of substrates and product are currently unknown, these values were fixed to be non-rate limiting. This model allowed us to incorporate an additional term to test the impact of reversible complex disassembly, which results in negligible activity of both enzymes under these assay conditions (Fig. 6, Scheme 5) (36,37). Initial values for the ratio $\left(k_{\text {off }} / k_{o n}\right)$ for complex assembly were set to be equal to the $K_{d}{ }^{a p p}$ derived from each SV-AUC isotherm experiment.

The resulting simulations showed that adding a reversible complex disassembly step to the reaction scheme only modestly improved fits to the lower temperature data (Fig. 6C), but did not improve the fits of the higher temperature data (Fig. 6D). In addition, Fitspace confidence contour analysis (64) showed that the derived $k_{\text {off }}$ value for the complex dissociation step was not constrained by the data (not shown), suggesting that the model is more complex. Closer examination of the high temperature data showed that several reactions failed to go to completion, suggesting the enzyme rapidly inactivates at higher temperatures. We therefore revised the working model to incorporate an irreversible enzyme inactivation step ( $k_{\text {inact }}$ ) (Figure 6 , Scheme 6). The resulting simulations resulted in good fits to both the low and high temperature datasets shown in Figs. 6E and 6F, respectively. In addition, Fitspace analysis showed that the derived pseudo-first order rate constants for monomethylation $\left(k_{m e 1}\right)$, and

322 dimethylation $\left(k_{m e 2}\right)$ reactions were reasonably well-constrained by the data (Fig. $6 \mathrm{G}$ and $\mathrm{H}$ ).

323 Furthermore, the rate of enzyme inactivation $\left(k_{\text {inact }}\right)$ was constrained by the data in the higher 324 temperature experiments (Fig. 6H) but not in the lower temperature experiments (Fig. 6G), 325 where enzyme inactivation is negligible. Figure 7 shows that the use of Scheme 6 produces 326 good fits for all datasets. 
obtained pseudo-first order rate constants for monomethylation $\left(k_{m e 1}\right)$, dimethylation $\left(k_{m e 2}\right)$ and the rate of enzyme inactivation ( $k_{\text {inact }}$ ) are summarized in Tables 2-4, respectively. At most of the tested enzyme concentrations, activity increased linearly as the temperature increased from $5^{\circ} \mathrm{C}$ to $20^{\circ} \mathrm{C}$ (Fig. $8 \mathrm{~A}$ and $\mathrm{C}$ ). However, above $20^{\circ} \mathrm{C}$, non-Arrhenius behavior was observed, as the rate of irreversible enzyme inactivation $\left(k_{\text {inact }}\right)$ rivaled or exceeded the rates of turnover (Tables 2-4), resulting in reactions that failed to go to completion (Fig. 7). These results are consistent with the conclusions from the SV-AUC analysis, which suggested that as the complex dissociates at higher temperatures, one or more of the subunits undergoes an irreversible conformational change that is not competent for catalysis. We therefore plotted $k_{m e 1}$ and $k_{m e 2}$ rates $\left(\operatorname{Ln}\left(k_{n)}\right)\right.$ as a function of temperature $(1 / \mathrm{T})$ between $5^{\circ} \mathrm{C}$ and $20^{\circ} \mathrm{C}$ to fit the data to the Arrhenius equation (Fig. $8 \mathrm{~B}$ and D, respectively). Linear fitting of the Arrhenius plots revealed similar values for the energy of activation $\left(E_{a}\right)$ between the tested concentrations. The average $E_{a}$ values were $10.9 \pm 2.0 \mathrm{kcal} \mathrm{K}^{-1} \mathrm{~mol}^{-1}$ and $17.8 \pm 4.7 \mathrm{kcal} \mathrm{K}^{-1} \mathrm{~mol}^{-1}$ for the monomethylation and dimethylation reactions, respectively.

The minimum enzyme concentration resulting in complete conversion into the monoand then dimethylated forms was $1.0 \mu \mathrm{M}$ at $15^{\circ} \mathrm{C}$ (Fig. 7). Slightly higher activity was observed at the same enzyme concentration at $20^{\circ} \mathrm{C}$, but with evidence of significant enzyme inactivation resulting in failure to go to completion. Increased concentration extended the range of temperatures under which complete conversion could be observed. For example, at $5 \mu \mathrm{M}$ enzyme concentration, complete conversion of the peptide into the dimethylated form was observed between $5^{\circ} \mathrm{C}$ and $30^{\circ} \mathrm{C}$, with evidence of modest $\mathrm{H} 3 \mathrm{~K} 4$ trimethylation activity $(7 \%$ $15 \%$ ) between $10^{\circ} \mathrm{C}$ and $25^{\circ} \mathrm{C}$ (Fig. 7). However, at $37^{\circ} \mathrm{C}$, only $\sim 25 \%$ of the peptide was converted into the dimethylated form before the enzyme was completely inactivated.

In general, the apparent pseudo first-order rate constants for mono- and dimethylation were correlated with the amount of holo-complex in the assay at every temperature between

$3545^{\circ} \mathrm{C}$ and $30^{\circ} \mathrm{C}$, with Pearson correlation coefficients ( $r$ ) ranging from 0.57-0.94 for monomethylation, and $0.46-0.86$ for dimethylation. At $37^{\circ} \mathrm{C}$, the correlation was less obvious due to the lack of detectable activity at the lowest concentrations. ( $r=0.17$ and 0.29 for mono and dimethylation, respectively). In contrast, the parameter that was most highly correlated with

358 the amount of holo-complex present in the assay at all temperatures was the rate of irreversible 359 enzyme inactivation $\left(k_{\text {inact }}\right)$, with Pearson $r$ values ranging between -0.84 and -0.99 , depending 360 on the concentration tested. These results are consistent with the conclusions from the $s_{w}$ 361 isotherm analysis, in that holo-complex formation prevents individual subunits from sampling 
potential non-productive folding intermediates, some of which lead to irreversible enzyme inactivation. These results also raise questions about how cells manage to prevent loss of enzymatic activity at physiological temperatures.

\section{Induced high local concentration within a biomolecular condensate alters the assembly} and enzymatic activity of the MLL1 core complex

Both hydrodynamic and enzymatic assays suggested that higher local concentrations of subunits would promote complex formation and enzymatic activity at physiological temperatures. However, given the low concentration of MLL1 in cells (which has been estimated to be femtomoles per mg of nuclear extract (65)), it is likely other factors are required to promote complex assembly. MLL1 has been shown to localize in discrete puncta in mammalian cell nuclei (66), raising the possibility that it could be regulated by induced high local concentration in liquid-liquid phase-separated (LLPS) particles, such as those found in transcription factories $(67,68)$. Liquid-liquid phase separation has been shown to increase local protein concentration of proteins and ligands by up to 10,000-fold (69). Common features of proteins that undergo phase separation include primary sequences with regions of low complexity, or intrinsically disordered regions, that provide the numerous transient multivalent interactions required for liquid-liquid de-mixing (70). Indeed, examination of the primary sequence of MLL1 by IUPred (71) reveals that the majority of its sequence is predicted to be intrinsically disordered (Fig. 9A). In addition, the MLL1 construct used in this investigation and each $\mathrm{WRAD}_{2}$ subunit shows significant regions of predicted disorder (Fig. S2). To determine if the catalytic module of the MLL1 core complex may also be regulated by phase separation, we examined MWRAD 2 using differential interference contrast (DIC) microscopy at concentrations up to $75 \mathrm{mg} / \mathrm{ml}$ but observed no evidence for phase separation (not shown). However, since a previous investigation showed increased enzymatic activity of the MLL1 core complex with reduced ionic strength (72), we tested whether reduced ionic strength may also regulate the LLPS properties of the MLL1 core complex.

First, we compared MLL1 core complex activity at several different ionic strengths at

391 found that the enzymatic activity was significantly increased in buffers with sub-physiological

392 ionic strength (Fig. 9B, D). While there was relatively little difference in mono- or dimethylation

393 activities between $200-100 \mathrm{mM} \mathrm{NaCl}$, mono- and dimethylation activity was increased 15- and

394 12-fold, respectively, when the $\mathrm{NaCl}$ concentration was reduced from 100 to $25 \mathrm{mM}$ (Fig. 9B, 
compared the hydrodynamic properties of the $5 \mu \mathrm{M} \mathrm{MWRAD}{ }_{2}$ complex at $100 \mathrm{mM}$ and $25 \mathrm{mM}$ $\mathrm{NaCl}$ at $25^{\circ} \mathrm{C}$ using SV-AUC (Fig. 9C). Strikingly, comparison of $c(s)$ profiles showed hydrodynamic changes in the complex that resembled those of HP1 $\alpha$ that was induced to undergo phase separation (73). The relatively monodisperse peak of the MLL1 core complex at physiological ionic strength (Fig. 9C, purple line) becomes more polydisperse when ionic strength is reduced (Fig 9C, blue line), with peaks at $8.1 S(54 \%), 10.0 S(21 \%)$ and $12.3 S$ $(\sim 10 \%)$, along with several higher molecular weight species that collectively account for $\sim 16 \%$ of the total signal. We also noticed that the relative distribution among these species shifts to larger $S$-values in a concentration-dependent manner, which is more pronounced with even lower ionic strength (Fig. S3). These results suggest that the increased activity of the MLL1 core complex with lower ionic strength is associated with hydrodynamic alterations of the complex that could include conformational alterations, oligomerization, aggregation, and/or phase separation.

Because the standard $c(s)$ analysis uses a single weight-average frictional coefficient of all particles to fit the data (74), the polydispersity of the sample at low ionic strength shown in Fig. 9C prevents accurate molecular weight estimates of each species - and thus our ability to

412 distinguish among the different hypotheses. We therefore performed a two-dimensional size and 413 shape distribution analysis $\left(c\left(s, f_{r}\right)\right)$ of the SV-AUC data, which allows estimation of the frictional 414 coefficients and average molar masses of each species in a complex distribution (75). The $415 c\left(s, f_{r}\right)$ distribution of $\mathrm{MWRAD}_{2}$ at $\sim 100 \mathrm{mM} \mathrm{NaCl}$ showed a single peak with the typical 416 experimental $s^{*}$-value of the complex, but encompassing a fairly broad range of frictional ratios 417 between 1.0 and 3.0, with a weight average frictional coefficient of $\sim 1.5$ (Fig. 9E). The estimated 418 average molecular mass using this frictional coefficient and S-value was $\sim 190 \mathrm{kDa}$, which is in 419 fairly good agreement with the theoretical mass of the monomeric complex (205 kDa). In 420 contrast, in low ionic strength buffer, the $c\left(s, f_{r}\right)$ distribution showed that the majority of the signal 421 is divided among several peaks with larger $S$-values that ranged between 9 and 16, with 422 evidence of several larger molecular weight species ranging between 20-70 S (Fig. 9F). Several 423 of the peaks between 9 and $13 S$ had frictional ratios that range between 1.1-1.2, which gave 424 mass estimates between 140-230 kDa. Because these species have relatively similar molar 425 mass estimates, these $S$-values likely correspond to species with increasingly compact 426 conformations of the monomeric MLL1 core complex. The peak at 16 S gives a mass estimate 427 of $\sim 350 \mathrm{KDa}$, which is indicative of a reaction boundary between monomeric and dimeric 428 complexes. These results suggest that lower ionic strength allows the complex to sample 429 different conformational states, some of which are more compact, and some that allow 
oligomerization of the MLL1 core complex. Consistent with this interpretation, these larger Svalue species become increasingly more populated in an $M W R A D_{2}$ concentration-dependent manner (Fig, S3).

The $c\left(s, f_{r}\right)$ analysis also showed several discrete species with $S$-values between 20-70 S with a broad range of frictional ratios ranging between 3-5 (Fig. 9F). Integration of these peaks gave mass estimates starting at $\sim 3.7 \mathrm{MDa}$, which approximates an 18-mer of $\mathrm{MWRAD}_{2}$, with each discrete species at higher $S$-values approximating the addition of one $M W R A D_{2}$ dimer. This hydrodynamic behavior is indicative of fiber-like material (76) and could reflect various sizes of insoluble aggregates, or the fiber-like polymerization that is predicted to precede the formation of phase separated droplets (Fig. 9G) (70,77). To distinguish these hypotheses, we examined enzymatic reaction mixtures at $100 \mathrm{mM}$ or $25 \mathrm{mM} \mathrm{NaCl}$ using DIC microscopy. Surprisingly, despite using a relatively low concentration of enzyme $(5 \mu \mathrm{M})$, the low ionic strength reaction mixture showed evidence of spherical LLPS droplets (Fig. 10B) that were absent in the $100 \mathrm{mM} \mathrm{NaCl}$ reaction mixture (Fig. 10A). No visible evidence of protein precipitation was observed. The droplets were small and mobile, but did not appear to fuse, which is a common feature of particles induced to undergo LLPS (77). However, addition of a crowding agent (dextran; $7 \% \mathrm{w} / \mathrm{v}$ ) to the reaction mixture resulted in LLPS droplets with larger diameters and observable fusion events that could be detected by DIC microscopy (Fig. 10C and movie S1). Importantly, the droplets disappeared in the presence of 5\% 1,6 hexanediol (Fig. 9D), which has been shown to disrupt LLPS droplets formed by other proteins (78). We also note that in the presence of dextran, similar LLPS droplets (Fig. S4) and hydrodynamic behavior Fig. S5) could be observed at concentrations of $\mathrm{NaCl}$ that more closely approximated physiological ionic strength.

Since we observed that higher concentrations of the histone $\mathrm{H} 3$ peptide alone showed evidence of phase separation (not shown), we next determined whether the LLPS droplets we observed contained only histone $\mathrm{H} 3$ or if they also contained the MLL1 core complex. To do this, we assembled the MLL1 core complex with fluorescently-labeled WDR5 (W*) or RbBP5

$457\left(R^{*}\right)$ subunits and, after purification by SEC, we tested for their ability to phase separate using 458 fluorescence microscopy. SEC elution profiles were similar to that of unlabeled complex (Fig 459 S6A) and SDS-PAGE showed that each fluorescent subunit eluted in a stoichiometric complex 460 with unlabeled subunits (Fig. S6B). In addition, control experiments with each complex showed 461 that the fluorescent tag had minimal effect on enzymatic activity (Fig. S6C, D). When reactions 462 were examined using fluorescent microscopy, both fluorescently labeled complexes were 463 present in the buffer and inside the droplets (Fig. 10E, F and movies S2, S3). These results 
suggest that the catalytic module of the MLL1 core complex is in an equilibrium between phases both inside and outside of the LLPS droplets.

Lastly, to determine if LLPS formation rescues enzymatic activity at physiological temperature, we compared methylation kinetics of different concentrations of the MLL1 core complex among reaction mixtures containing $200 \mathrm{mM}$ or $25 \mathrm{mM} \mathrm{NaCl}$ at $37^{\circ} \mathrm{C}$. As described above, at near physiological ionic strength, none of the reactions went to completion, even after 24-hour incubation, mainly due to rapid enzyme inactivation at $37^{\circ} \mathrm{C}$ (Fig. 11, left column). In contrast, in low ionic strength buffer, most of the tested concentrations showed at least $80 \%$ conversion to the dimethylated form of $\mathrm{H} 3 \mathrm{~K} 4$ after only 5 minutes (Fig. 11, right column). At the highest concentrations tested $(5 \mu \mathrm{M})$ the pseudo-first order rate constants for mono- and dimethylation increased 62- and 50-fold, respectively, with no evidence of enzyme inactivation (Table 5). Lastly, unlike the reactions using higher ionic strength, at low ionic strength, the reactions better approximated true single-turnover conditions with rates that were strictly dependent on enzyme concentration and not substrate concentration (79) (Fig. S7), as would be expected upon induced high-local concentration of enzyme within a biomolecular condensate.

All together, these results are consistent with the hypothesis that induced high-local concentration within a biomolecular condensate overcomes the thermodynamic barrier for MLL1 core complex assembly at physiological temperatures.

\section{DISCUSSION}

Numerous studies have established the role of MLL1 in the regulation of the degree of

486 that the SET domain has intrinsic H3K4 monomethylation activity, several studies have shown

487 that multiple methylation depends on interaction of MLL1 with the WRAD 2 sub-complex. While

488 the molecular details for this product specificity switch are still in question, the idea that

489 regulated complex assembly controls the spatial and temporal deposition of different H3K4

490 methylation states has significant experimental support. The importance of understanding the

491 molecular details of this mode of regulation is demonstrated by studies showing targeted

492 inhibition of the Win motif-WDR5 protein-protein interaction within the MLL1 core complex

493 selectively reduces proliferation of MLL1-translocation leukemias and other cancer cells (42-

494 44,80). These results suggest that molecules mimicking the Win motif, collectively called Win 495 motif inhibitors, may be useful alternative or complementary therapeutics for cancer. 
However, progress in exploiting this potential has been impeded by the lack of understanding of the biophysical and thermodynamic mechanisms that underlie MLL1 core complex assembly. The lack of standardized in vitro assay conditions has resulted in different conclusions regarding the mechanisms of multiple lysine methylation by SET1 family complexes and identification of the best inhibitors. For example, we previously found that the same Win motif inhibitor gives $\mathrm{IC}_{50}$ values that vary by more than an order of magnitude when assayed over a relatively narrow concentration range of the MLL1 core complex (0.5-1.8 $\mu \mathrm{M})$ (81), suggesting complex assembly is relatively labile. Missing is a complete understanding of the conditions under which the complex is assembled when assayed in vitro. This is crucial not only for our ability to compare the potency and specificity of different inhibitors, but also for establishing a baseline for understanding how the dynamics of MLL1 core complex assembly is regulated in cells.

In this investigation, we systematically characterized the hydrodynamic and kinetic properties of a reconstituted human MLL1 core complex under a variety of assay conditions. As expected, we found that complex assembly is highly concentration and temperature dependent.

511 Consistent with the hypothesized hierarchical assembly pathway, we found that the holo-

512 complex assembles through interactions between the MW and $\mathrm{RAD}_{2}$ sub-complexes, and that

513 this assembly correlated with enzymatic activity. However, unexpectedly, we also found that the

514 disassembled state of the complex is favored at physiological temperatures and at the sub-

515 micromolar enzyme concentrations typically used in steady-state enzymatic assays (in which

516 the substrate is in vast excess compared to the concentration of enzyme). We found that the

517 complex disassembly results in rapid and irreversible enzyme inactivation under these

518 conditions, likely because one or more subunits samples unproductive conformational states.

519 Consistent with this conclusion, it was previously shown that overexpression of C-terminal

520 fragments from the human SETd1A protein in mammalian cells depletes $\mathrm{WRAD}_{2}$ subunits from

521 the endogenous SETd1A and SETd1B paralogs, resulting in their degradation (82). It is possible

522 that in the cell, unproductive folding intermediates are limited by interaction with chaperones.

523 Consistent with this hypothesis, HSP70 and HSP90 proteins have been found to co-purify with

524 MLL1 super-complexes (31,33). In addition, HSP90 has been shown to be required for the

525 stability of human MLL1 and the Drosophila melanogaster ortholog, Trithorax, which is important

526 for homeotic gene expression (83). It remains to be determined if these or other chaperones

527 interact with and regulate folding of the subunits of the catalytic module.

528 Our data suggest that the $\mathrm{MW}$ and $\mathrm{RAD}_{2}$ sub-complexes interact with a $K_{d}^{\text {app }}$ of $\sim 6 \mu \mathrm{M}$ at

$52937^{\circ} \mathrm{C}$, raising the question of how complex forms in cells that contain relatively few molecules of 
530 MLL1, which has been estimated to be femtomoles per mg of nuclear extract (65). WRAD 2

531 subunits appear to be present in cells in vast excess compared to that of MLL1 (65), which

532 could help overcome the thermodynamic barrier to complex assembly. However, our previous

533 demonstration that a stoichiometric excess of WDR5 inhibits the enzymatic activity of MLL3 (84)

534 and MLL1 (unpublished) core complexes argues against this possibility. Our data suggest that

535 inhibition by excess WDR5 results from saturation of available binding sites on the $\mathrm{RAD}_{2}$ sub-

536 complex, which would prevent its interaction with the MW sub-complex. These results suggest

537 that cellular pools of WDR5 may need to be compartmentalized to prevent this form of inhibition

538 of SET1 family complexes. This may explain why WDR5 over-expression is associated with

539 several poor outcome malignancies, including bladder, breast, colon, and prostate cancers,

540 leukemias and hepatocellular carcinomas (80,85-89).

541 Alternative possibilities to overcome the barrier to complex formation in cells include

542 interaction with other unknown proteins, cofactors, nucleic acids, post translational

543 modifications, and/or by inducing a high local concentration of $M W R A D_{2}$ subunits within a phase

544 separated compartment. While there is evidence that phosphorylation and long non-coding

545 RNAs regulate the function of MLL family complexes $(90,91)$, it is currently unclear if these

546 mechanisms would overcome the barrier to MLL1 core complex assembly at physiological

547 temperatures. Our data suggests that the barrier to complex formation is overcome in cells by

548 concentration of subunits in biomolecular condensates, such as those found in transcription

549 factories (67). Biomolecular condensates are membraneless liquid-like organelles, or

550 intracellular phase-separated compartments, that function to concentrate proteins and nucleic

551 acids to regulate a variety of biological processes $(77,92)$. This form of compartmentalization

552 has been shown to have variable effects on the activity of enzymes, ranging from a 2-70-fold

553 stimulation in the rate of enzyme or ribozyme-catalyzed cleavage reactions, to inhibition of

554 catalyzed reactions, protein conformational alterations and increased thermal resistance $(79,93-$

555 97). While there are a number of recent examples of chromatin and chromatin-associated

556 proteins that undergo LLPS in mechanisms that may regulate heterochromatic gene silencing

$557(69,73,98-100)$, to our knowledge, there is currently no evidence demonstrating LLPS regulation

558 of enzymatic activity of a histone modification enzyme.

559 Our data suggest that concentration of the MLL1 core complex in a biomolecular

560 condensate overcomes the barrier to complex assembly at physiological temperatures, resulting

561 in histone methyltransferase activity that is increased by at least 30-60-fold (Table 5), depending

562 on the enzyme concentration in the assays. However, the molecular mechanism for how

563 compartmentalization stimulates $\mathrm{MWRAD}_{2}$ activity is likely more complex. This is because the 
564 hydrodynamic properties of the complex change under phase separation conditions, likely

565 involving conformational changes and oligomerization that may be prerequisites for the

566 multivalent interactions required for LLPS. It is interesting to note that in the absence of a

567 crowding agent, these hydrodynamic changes begin to occur at the lower boundary of

568 physiological ionic strength. This suggests a plausible regulatory mechanism in which small

569 changes in ionic strength, possibly through compartmentalization, could have a large impact on

570 MLL1 core complex activity. However, we also note that further lowering the ionic strength of the

571 buffer ( $<50 \mathrm{mM}$ ) resulted in detection of up to six methylation events on the same peptide (Fig.

572 S8), suggesting reduced enzyme specificity. This result, may help explain contradictory results

573 from different labs using different assay conditions. In addition, differences in the stability of MLL

574 family complexes may underlie different conclusions about their relative activities. For example,

575 we and others have observed that the MLL3 core complex is significantly more stable than the

576 other MLL family complexes $(53,84,101)$, which may account for observations suggesting that

577 the MLL3 core complex is more active $(72,102)$. However, we have found that when comparing

578 enzymes under conditions where complexes are at least $80 \%$ assembled, there is little

579 difference in the overall rate of H3K4 monomethylation among SET1 family complexes (84). Our

580 results here underscore the importance of assaying enzymes under conditions where

581 complexes are fully assembled, which in several cases may preclude the use of low enzyme

582 concentrations typically used in steady-state kinetics studies.

583 Our results suggest a model in which MLL1 enzymatic activity is regulated in the cell at

584 the level of complex assembly within a phase-separated transcription factory. Several lines of

585 experimental evidence are consistent with this hypothesis. Early confocal microscopy studies

586 showed that transcription occurs in a defined number of discrete sites within the cell called

587 transcription factories $(103,104)$, each containing a protein-rich core that encompasses RNA

588 polymerase (Pol) II, co-activators, chromatin remodelers, transcription factors, histone

589 modification enzymes, ribonucleoproteins, RNA helicases, splicing and processing factors

590 (105). Indeed, peptides derived from WDR5 and DPY30, the two most abundant MLL1 core

591 complex subunits (65), were found in purified RNA Pol II transcription factories (105). A phase

592 separation model may explain, in part, immunofluorescence experiments showing that MLL1

593 has a punctate distribution within mammalian cell nuclei (66), which is a common feature of

594 proteins that undergo LLPS (77). Furthermore, use of the PScore (106) and CatGRANULE

595 (107) LLPS prediction programs show that MLL1, as well as all human MLL family proteins,

596 have high phase separation probabilities (Table S3), as does Ash2L and Ash2L-containing sub-

597 complexes (Table S4). In addition, it was recently demonstrated that the multivalent interactions 
598 provided by the carboxyl-terminal domain (CTD) of RNA polymerase (Pol) II are sufficient for

599 formation of RNA Pol II LLPS clusters (78). Since several studies suggest that RNA Pol II

600 interacts directly with MLL1 $(108,109)$, it is possible they function together within phase-

601 separated transcription factories. Consistent with this model, ChIP studies show that MLL1 and

602 RNA Pol II co-localize at nucleosomes throughout the promoters and open reading frames of

603 actively-transcribed genes (109). However, a puzzling aspect of this model is that, despite a

604 study showing that MLL1 can be pulled-down from nuclear extracts with a recombinant GST-

605 CTD fusion protein (109), Pol II appears to be absent in purified MLL1 super-complexes (30-33).

606 It may be that co-localization within the same transcription factory is required for the interaction.

607 Combining our results on the assembly of the catalytic module with the observation that

608 it follows a large region of predicted intrinsic disorder in the primary sequence of MLL1 (Fig. 9A),

609 we propose a "swinging domain" model for the mechanism of action of the MLL1 core complex

610 within cellular transcription factories (Fig. 12). A swinging domain is a common feature of

611 enzyme complexes involved in multistep assembly pathways and are characterized by a

612 structured mobile domain tethered to other components by conformationally flexible linker

613 regions (110). This may explain why the low complexity region is conserved not only among

614 MLL1 orthologs, but also in the primary sequences in all human SET1 family members, with the

615 main differences being the length of the linker regions that precedes the SET domain (Fig. S9).

616 This observation suggests that a swinging domain may be a conserved feature of SET1 family

617 complexes (Fig. S10D) and linker length differences could be a unique regulatory feature that

618 limits the range of nucleosomes that can be reached within different transcriptional

619 compartments. This hypothesis deserves further investigation.

620 A swinging domain model where the SET domain-WDR5 complex swings to different

621 nucleosomes provides a satisfying explanation for how the relatively few molecules of MLL1 in

622 the cell could methylate multiple nucleosomes in the promoter and open reading frames of

623 genes as they move through the transcription factory (Fig. 12). This model also provides a

624 plausible explanation for the observation of MLL1 and RNA Pol II co-localization in ChIP

625 experiments without the necessity of a physical interaction. Given that $R A D_{2}$ subunits are

626 relatively abundant in cells and that the $\mathrm{RAD}_{2}$ sub-complex interacts with nucleosomes in the

627 absence of the MW sub-complex (manuscript in preparation), concentration of both sub-

628 complexes within a transcription factory could provide the energy required to overcome the

629 barrier for holo-complex formation at physiological temperatures, resulting in activation of the

630 histone methyltransferase activity of the MLL1 core complex. This model provides an elegant

631 "switch-like" mechanism for spatiotemporal control of H3K4 methylation through the rapid 
632 formation or dissolution of biomolecular condensates, which would ultimately regulate the

633 hierarchical assembly of the MLL1 core complex.

\section{ACKNOWLEDGEMENTS}

636

We thank John Sfakis for help with the Fluorescent labeling experiments and Connie

638 to the Zeiss light microscope and Brian Haarer for assistance with the microscopy. We also

639 thank Steve Hanes, Bruce Knutson and Alaji Bah for helpful suggestions and Ashley Canning

640 and Michael Connelly for critical reading of the manuscript. This work was supported in part by

641 R01C140522 (to M.S.C.).

642

\section{METHODS}

644 Protein Expression and Purification

Each of the human genes for the MLL1 SET domain (a.a. 3745-3969 - Uniprot \#: Q03164), WDR5 (2-334 - P61964), RbBP5 (1-538 - Q15291) and Ash2L (1-534 - Q9UBL3-3) (111) were cloned into the pST44 polycistronic vector (112). The WDR5 subunit was cloned with an N-terminal 6x-Histidine tag followed by a Tobacco Etch Virus (TEV) protease cleavage site. Plasmids were transformed into Rosetta pLysS BL21 E. coli cells and plated on LB agar supplemented with $50 \mu \mathrm{g} / \mathrm{mL}$ carbenicillin and $20 \mu \mathrm{g} / \mathrm{mL}$ chloramphenicol (both from Gold Biotechnology). Individual colonies were used to inoculate a seed culture of $50 \mathrm{~mL}$ of Terrific

652 Broth II (MP Biomedicals), again supplemented with carbenicillin and chloramphenicol and 653 grown overnight at $30^{\circ} \mathrm{C} .20 \mathrm{~mL}$ of the seed culture were used to inoculate $1 \mathrm{~L}$ of Terrific Broth II 654 media in baffled $2800 \mathrm{~mL}$ flasks, maintaining the antibiotic resistance. Cultures were then grown 655 for $2-4 \mathrm{hrs}$ at $37^{\circ} \mathrm{C}$ and 200RPM shaking until the O.D.600 reached $\sim 1$. Cultures were then chilled for $1 \mathrm{hr}$ at $4^{\circ} \mathrm{C}$ followed by induction with $1 \mathrm{mM}$ Isopropyl $\beta$-D-1-thiogalactopyranoside 657 (IPTG - Gold Biotechnology), after which cells were grown for an additional $20-22 \mathrm{hrs}$ at $16^{\circ} \mathrm{C}$ 658 with constant shaking. Cells were harvested by centrifugation at $4^{\circ} \mathrm{C}$ and pellets were flash 659 frozen in liquid nitrogen and stored at $-80^{\circ} \mathrm{C}$ until they could be lysed. Frozen cells were thawed 660 and resuspended in $50 \mathrm{~mL}$ of lysis buffer $(50 \mathrm{mM}$ Tris- $\mathrm{HCl}, \mathrm{pH} 7.5 ; 300 \mathrm{mM} \mathrm{NaCl} ; 30 \mathrm{mM}$ 661 Imidazole; $3 \mathrm{mM}$ dithiothreitol (DTT) and $1 \mu \mathrm{M} \mathrm{ZnCl}_{2}$, supplemented with one tablet of EDTA-free 662 protease inhibitor cocktail (Roche)), lysed with a microfluidizer, and cleared by centrifugation at $66317,000 \mathrm{RPM}$ at $4^{\circ} \mathrm{C}$ for $30 \mathrm{~min}$. The supernatant was diluted to $250 \mathrm{~mL}$ in Buffer 1 (50mM Tris$664 \mathrm{HCl}, \mathrm{pH} 7.5 ; 300 \mathrm{mM} \mathrm{NaCl} ; 30 \mathrm{mM}$ Imidazole; $3 \mathrm{mM}$ DTT and $1 \mu \mathrm{M} \mathrm{ZnCl}_{2}$ ) and flowed over a 
HisTrap 5mL nickel affinity column (GE) using an AKTA Purifier FPLC (GE) at a rate of 0.5 $\mathrm{mL} /$ minute. Bound complex was washed with 10 column volumes (CV) of Buffer 1 at $1 \mathrm{~mL} / \mathrm{min}$., and then eluted with a 25-CV linear gradient of Buffer 2 (Buffer 1 with 500 mM imidazole). Fractions containing the MWRA complex were pooled, supplemented with GST-6x-His-TEV protease to a final concentration of $0.1 \mathrm{mg} / \mathrm{mL}$ and dialyzed against Buffer 1 with three changes. The complex was then passed over a re-equilibrated HisTrap column and fractions from the

671 flow-through containing the cleaved MWRA sample were collected, concentrated by

672 ultrafiltration using a $30 \mathrm{kDa}$ cutoff membrane to $\sim 12 \mathrm{mg} / \mathrm{mL}$, and further purified by size-

673 exclusion chromatography (SEC) using a Superdex 200 (16/60) column (GE) pre-equilibrated

674 with Buffer $3(20 \mathrm{mM}$ Tris- $\mathrm{HCl}$, pH 7.5; $300 \mathrm{mM} \mathrm{NaCl} ; 1 \mathrm{mM}$ TCEP and $1 \mu \mathrm{M} \mathrm{ZnCl}$ ). A two-fold

675 Molar excess of Human DPY-30 (1-99 - Q9C005), expressed and purified as previously

676 described (36), was added to the MWRA sample and the resultant complex was purified with

677 multiple rounds of SEC in buffer 3. Fractions containing purified $\mathrm{MWRAD}_{2}$ were concentrated to

$67812 \mathrm{mg} / \mathrm{mL}$, aliquoted, flash frozen, and stored at $-80^{\circ} \mathrm{C}$ until use. Individual subunits for

679 Bayesian experiments were purified as previously described (36).

\section{Sedimentation Velocity-Analytical Ultracentrifugation}

682 Experimental Procedures. All stock protein samples were thawed on ice, diluted to the desired 683 concentration, and spun at 15,000RPM for $15 \mathrm{~min}$. at $4^{\circ} \mathrm{C}$ using a Thermo Scientific tabletop 684 refrigerated centrifuge to remove any debris. Protein concentrations were measured with a 685 NanoDrop spectrophotometer using the extinction coefficient $\varepsilon^{280}$ of $248,954 \mathrm{M}^{-1} \mathrm{~cm}^{-1}$, which was predicted from the amino acid sequence using ProtParam (113). 100 or $400 \mu \mathrm{L}$ of diluted

687 protein samples were then loaded into AUC cells containing 3- or 12-mm two-sector charcoal-

688 Epon centerpieces (SpinAnalytical) assembled with quartz or sapphire windows. Matching 689 buffer was loaded into the reference sector of each cell. AUC cells were then loaded into a Ti-60 690 4-hole Beckman-Coulter rotor, pre-equilibrated to the specific run temperature for at least $4 \mathrm{hrs}$.

691 Rotors were then inserted into the chamber of the centrifuge and allowed to re-equilibrate to 692 experimental temperature for a minimum of $2 \mathrm{hrs}$ before initiation of the run. Sedimentation 693 velocity analytical ultracentrifugation (SV-AUC) was performed using a Beckman-Coulter

694 Proteomelab XL-A analytical ultracentrifuge equipped with absorbance optics. Each run was 695 preceded by a 3000-rpm wavelength scan to detect cell leakage and to select the appropriate 696 wavelength to ensure a starting absorbance of between 0.25 and 1.2 OD units. Wavelengths at 697 or near the maximal absorbance for aromatics of $280 \mathrm{~nm}$ or peptide backbone of $230 \mathrm{~nm}$ were 698 selected, depending on the protein concentration and pathlength of the centerpiece. Without 
slowing the rotor, a method scan of 50,000-rpm was initiated, and 200 scans/cell were collected with the time interval between scans set to zero. Each experiment was replicated in duplicate or

701 triplicate.

Data Analysis. Lamm equation modeling of all SV-AUC results was performed using the continuous distribution ( $c(s)$ ) method in SEDFIT (56). Maximum entropy (ME) regularization using a confidence level of $P=0.68$ was performed to identify the most parsimonious distribution consistent with the data, and the fits for each experiment gave acceptable RMSD values ranging between 0.003 and 0.01 . Density, viscosity and partial specific volume values were estimated by inputting the temperature, buffer reagents, and amino acid sequences of all five complex components (assuming a DPY-30 dimer) into the SEDNTERP program (114), and the values used are listed in Table S5. The resulting $c(s)$ distributions were displayed and further analyzed using GUSSI (115). To determine the amount of holo-complex under each

712 condition, distributions were integrated between S-values 6.8 and 7.6, which represents one

713 standard deviation from the mean S-value of the holo-complex peak over all conditions, which

714 was $7.2+/-0.4$. For binding analyses, $c(s)$ distributions were integrated from 0.5 to $9.5 S$ to derive the corresponding signal-weighted average sedimentation coefficients $\left(s_{w}\right)$, which were plotted as a function of loading concentration at each temperature and fit with mass action law models using the program SEDPHAT (116).

For Bayesian analyses of c(s) distributions, expected sedimentation coefficients were derived from separate SV-AUC experiments of individual subunits or assembled sub-

720 complexes, which were each run at concentrations ranging from 0.25 to $5 \mu \mathrm{M}$ at $25^{\circ} \mathrm{C}$ (the data

721 for $0.25 \mu \mathrm{M}$ runs are shown in Fig. S1). These values were then used in ME regularization as

722 prior expectation restraints to give $c^{(p)}(s)$ distributions of the holo-complex at $25^{\circ} \mathrm{C}$. Prior

723 expectations for sub-complexes or individual subunits were implemented as Gaussians in

724 SEDFIT for Bayesian analysis, with a peak width of sigma $=0.2 S$ and centered at the weight-

725 average $S$-value of the main peak observed in the individual experiments with an amplitude of

7260.05 OD units. Since the prior expected S-values for WDR5 or RbBP5 overlapped when run in

727 individual experiments, they were used as prior expectations in $c^{(p)}(s)$ distributions to test the

728 concerted assembly mechanism with the same weight average $S$-value but with an amplitude 729 that was doubled (Fig. 5D). Each $c^{(p)}(s)$ distribution was fit with the same prior expectation for

$730 \mathrm{MWRAD}_{2}$, which used the weight-average $S$-value determined at $25^{\circ} \mathrm{C}$ and $0.25 \mu \mathrm{M}$ with a width 731 of sigma $=0.4 \mathrm{~S}$ and an amplitude of $0.3 \mathrm{OD}$ units. 
For the $c\left(s, f_{r}\right)$ analysis, the data were first imported into SEDFIT with reduced radial resolution $(0.006 \mathrm{~cm}$ compared to the default $0.003 \mathrm{~cm})$ and loading every second scan, to reduce the computational power required (60). These were fit using the $c\left(s, f_{r}\right)$ method in SEDFIT with resolutions of 50 for both the sedimentation coefficient and frictional ratio

736 dimensions.

\section{Methyltransferase Activity Assay}

$M_{W R A D}$ complex was assayed using a label-free quantitative MALDI-TOF mass

$741250 \mu \mathrm{M}$ S-adenosylmethionine (AdoMet) and reaction buffer (50 mM Tris, pH 9.0; $200 \mathrm{mM}$

$742 \mathrm{NaCl} ; 5 \%(\mathrm{v} / \mathrm{v})$ glycerol; $1 \mu \mathrm{M} \mathrm{ZnCl}$; 3 mM DTT), which were preincubated for 5 minutes at the

743 experimental temperature in a thermocycler. Reactions were initiated by the addition of

744 temperature-pre-equilibrated histone $\mathrm{H} 3$ peptide (residues 1-20, with an additional C-terminal

745 GGK-biotin moiety) to a final concentration of $10 \mu \mathrm{M}$. At various timepoints, a $2 \mu \mathrm{L}$ aliquot was

746 removed and quenched by mixing with $2 \mu \mathrm{L}$ of $1 \%$ trifluoroacetic acid (TFA). Quenched

747 reactions were stored at $-20^{\circ} \mathrm{C}$ until they could be analyzed. Upon analysis, samples were

748 thawed and $1 \mu \mathrm{L}$ of each was mixed with $4 \mu \mathrm{L}$ of $\alpha$-cyano-4-hydroxycinnamic acid in $0.05 \%$ TFA

749 and $50 \%$ acetonitrile. $2 \mu \mathrm{L}$ of this mixture for each time point was spotted onto a ground steel

750 target plate and allowed to dry at room temperature for 3-12 hours. Spectra were acquired on a

751 Bruker Autoflex III MALDI-TOF mass spectrometer in reflectron mode. Each spectrum was the

752 sum of at least 1000 individual laser shots, obtained from five different positions around the

753 spot, with 200 shots at each position. Using FlexAnalysis software (Bruker), the intensities of

754 the unmodified (m/z $2651 \mathrm{Da})$, mono- (m/z $2665 \mathrm{Da})$, di- (m/z $2679 \mathrm{Da})$, and trimethylated (m/z

$7552693 \mathrm{Da}$ ) species were summed to obtain the total intensity. The relative amount of each

756 species was then determined by dividing the intensity of each methylation state by the total

757 intensity at each time point and multiplied by the starting substrate concentration $(10 \mu \mathrm{M})$ to give

758 the micromolar concentration of each methylation state. These data were then plotted as a

759 function of time for kinetics analyses.

760 Fitting of the data was performed using the numerical integration of rate equations 761 approach implemented in KinTek Explorer software version 6.3 (61). For reaction schemes

762 incorporating the complex dissociation step, the ratio $\left(k_{\text {off }} / k_{\text {on }}\right)$ was constrained to be equal to

763 estimated $K_{d}{ }^{a p p}$ for complex dissociation at each temperature determined from the

764 sedimentation velocity $s_{w}$ isotherm analysis, with the $k_{o n}$ fixed at the limit of diffusion. All other 
non-variable parameters were fixed with non-rate limiting values. Confidence contour analysis using a $\mathrm{Chi}^{2}$ threshold of 0.9 was used to obtain estimates for the extent to which each variable parameter was constrained by the data.

\section{Labeling and assembly of fluorescent $M W R A D_{2}$ complexes}

Recombinant WDR5 or RbBP5 were expressed and purified as previously described (37). Purified proteins at $\sim 14 \mathrm{mg} / \mathrm{ml}$ were dialyzed into labeling buffer composed of $20 \mathrm{mM}$ HEPES, pH 7.0; $300 \mathrm{mM} \mathrm{NaCl} ; 1 \mathrm{mM}$ TCEP and $1 \mu \mathrm{M} \mathrm{ZnCl}_{2}$. The neutral pH was chosen to facilitate selective labeling of the free amino terminus of the protein, which has a lower $p K_{a}$ than the primary amines of the lysine side chains (117). The protein was mixed with AlexaFluor ${ }^{\mathrm{TM}}$ 488 NHS Ester (Invitrogen) in a 1:6 (for WDR5) or 1:5 (for RbBP5) molar excess of label and reacted for 3 hours at $4^{\circ} \mathrm{C}$. The entire reaction volume for each protein was then loaded onto a Superdex ${ }^{\text {TM }} 200$ 10/300 GL size-exclusion column (GE) to separate the labeled protein from the unreacted fluorophore. The labeled protein fractions were then combined and concentrated by ultrafiltration in a 10,000 MWCO concentrator (Millipore). Once concentrated, the degree of labeling was determined using the equations shown below:

$$
A_{\text {protein }}=A_{280}-A_{\max } *(\text { correction factor })
$$

$$
A_{\text {protein }} /\left(\text { pathlength } * \varepsilon_{\text {protein }}\right)=[\text { protein }]
$$

Degree of labeling $=\left(A_{\max } *(\right.$ protein $\left.M W)\right) /\left([\right.$ protein $\left.] * \varepsilon_{\text {dye }}\right)$

The degree of labeling for WDR5 $\left(\mathrm{W}^{*}\right)$, was found to be 1.1 , or $\sim 1$ molecule of fluorophore for each molecule of WDR5. The degree of labeling determined for RbBP5 $\left(R^{*}\right)$ was 1.9 , or $\sim 2$ molecules of fluorophore per molecule of RbBP5. Each labeled protein was then mixed in equivalent molar ratios with the other recombinant, unlabeled complex components and loaded onto a Superdex ${ }^{\mathrm{TM}} 200$ 10/300 GL size-exclusion column and fractions containing stoichiometric complex were pooled, concentrated, and stored at $-80^{\circ} \mathrm{C}$ until use.

\section{Liquid-Liquid Phase Separation (LLPS) Assays}

$\mathrm{MWRAD}_{2}$ at a concentration of $5 \mu \mathrm{M}$ was mixed with $\mathrm{H}^{1-20}$ peptide $(100-500 \mu \mathrm{M})$ and $250 \mu \mathrm{M}$ SAM in either physiological ( 100-150 mM) or sub-physiological ( 25-50 mM) NaCl 
798 buffers containing (50 mM Tris, $\mathrm{pH}$ 9.0, $1 \mu \mathrm{M} \mathrm{ZnCl}_{2}, 3 \mathrm{mM}$ DTT and 5\% (w/v) glycerol) in the 799 presence or absence of $7 \%(w / v)$ Dextran Sulfate (avg. M.W. $=500,000 \mathrm{Da})$ as a crowding 800 agent. $1 \mu \mathrm{L}$ of each sample was pipetted into the depression of 12 -well precleaned frosted end 801 Bioworld microscope slide, covered by a cover slip, and observed on a Zeiss light microscope in 802 DIC mode at 40x magnification. Single images and movies were taken using a Hamamatsu 803 camera connected to the microscope. All images taken are of samples at room temperature $804\left(\sim 23^{\circ} \mathrm{C}\right)$. In addition to $\mathrm{DIC}, \mathrm{M}\left(\mathrm{W}^{*}\right) \mathrm{RAD}_{2}$ or $\mathrm{MW}\left(\mathrm{R}^{*}\right) A D_{2}$ were imaged with the FITC filter 805 activated. As a control for phase separation, reaction mixtures were compared in the presence 806 and absence of $5 \% 1,6$ hexanediol.

807 


\section{REFERENCES}

1. Ruthenburg, A. J., Allis, C. D., and Wysocka, J. (2007) Methylation of lysine 4 on histone H3: intricacy of writing and reading a single epigenetic mark. Mol Cell 25, 15-30

2. Liu, C. L., Kaplan, T., Kim, M., Buratowski, S., Schreiber, S. L., Friedman, N., and Rando, O. J. (2005) Single-nucleosome mapping of histone modifications in S. cerevisiae. PLoS Biol 3, e328

3. Pokholok, D. K., Harbison, C. T., Levine, S., Cole, M., Hannett, N. M., Lee, T. I., Bell, G. W., Walker, K., Rolfe, P. A., Herbolsheimer, E., Zeitlinger, J., Lewitter, F., Gifford, D. K., and Young, R. A. (2005) Genome-wide map of nucleosome acetylation and methylation in yeast. Cell 122, 517-527

4. Santos-Rosa, H., Schneider, R., Bannister, A. J., Sherriff, J., Bernstein, B. E., Emre, N. C., Schreiber, S. L., Mellor, J., and Kouzarides, T. (2002) Active genes are tri-methylated at K4 of histone H3. Nature 419, 407-411

5. Wysocka, J., Swigut, T., Xiao, H., Milne, T. A., Kwon, S. Y., Landry, J., Kauer, M., Tackett, A. J., Chait, B. T., Badenhorst, P., Wu, C., and Allis, C. D. (2006) A PHD finger of NURF couples histone $\mathrm{H} 3$ lysine 4 trimethylation with chromatin remodelling. Nature $\mathbf{4 4 2}, \mathbf{8 6 -}$ 90

6. Santos-Rosa, H., Schneider, R., Bernstein, B. E., Karabetsou, N., Morillon, A., Weise, C., Schreiber, S. L., Mellor, J., and Kouzarides, T. (2003) Methylation of histone H3 K4 mediates association of the Isw1p ATPase with chromatin. Mol Cell 12, 1325-1332

7. Sims, R. J., 3rd, Chen, C. F., Santos-Rosa, H., Kouzarides, T., Patel, S. S., and Reinberg, D. (2005) Human but not yeast CHD1 binds directly and selectively to histone H3 methylated at lysine 4 via its tandem chromodomains. J Biol Chem 280, 41789-41792

8. Pray-Grant, M. G., Daniel, J. A., Schieltz, D., Yates, J. R., 3rd, and Grant, P. A. (2005) Chd1 chromodomain links histone H3 methylation with SAGA- and SLIK-dependent acetylation. Nature 433, 434-438

9. Kim, T., and Buratowski, S. (2009) Dimethylation of H3K4 by Set1 recruits the Set3 histone deacetylase complex to 5 ' transcribed regions. Cell 137, 259-272

10. Heintzman, N. D., Stuart, R. K., Hon, G., Fu, Y., Ching, C. W., Hawkins, R. D., Barrera, L. O., Van Calcar, S., Qu, C., Ching, K. A., Wang, W., Weng, Z., Green, R. D., Crawford, G. E., and Ren, B. (2007) Distinct and predictive chromatin signatures of transcriptional promoters and enhancers in the human genome. Nat Genet 39, 311-318

11. Hu, D., Gao, X., Morgan, M. A., Herz, H. M., Smith, E. R., and Shilatifard, A. (2013) The MLL3/MLL4 branches of the COMPASS family function as major histone H3K4 monomethylases at enhancers. Mol Cell Biol 33, 4745-4754

12. Lee, J. E., Wang, C., Xu, S., Cho, Y. W., Wang, L., Feng, X., Baldridge, A., Sartorelli, V., Zhuang, L., Peng, W., and Ge, K. (2013) H3K4 mono- and di-methyltransferase MLL4 is required for enhancer activation during cell differentiation. eLife 2, e01503

13. Cheng, J., Blum, R., Bowman, C., Hu, D., Shilatifard, A., Shen, S., and Dynlacht, B. D. (2014) A role for H3K4 monomethylation in gene repression and partitioning of chromatin readers. Mol Cell 53, 979-992 
14. van Dijk, K., Marley, K. E., Jeong, B. R., Xu, J., Hesson, J., Cerny, R. L., Waterborg, J. H., and Cerutti, H. (2005) Monomethyl histone H3 lysine 4 as an epigenetic mark for silenced euchromatin in Chlamydomonas. Plant Cell 17, 2439-2453

15. Bryk, M., Briggs, S. D., Strahl, B. D., Curcio, M. J., Allis, C. D., and Winston, F. (2002) Evidence that Set1, a factor required for methylation of histone $H 3$, regulates rDNA silencing in S. cerevisiae by a Sir2-independent mechanism. Curr Biol 12, 165-170

16. Krogan, N. J., Dover, J., Khorrami, S., Greenblatt, J. F., Schneider, J., Johnston, M., and Shilatifard, A. (2002) COMPASS, a histone H3 (Lysine 4) methyltransferase required for telomeric silencing of gene expression. J Biol Chem 277, 10753-10755

17. Nislow, C., Ray, E., and Pillus, L. (1997) SET1, a yeast member of the trithorax family, functions in transcriptional silencing and diverse cellular processes. Mol Biol Cell 8 , 2421-2436

18. Wong, S. H., Goode, D. L., Iwasaki, M., Wei, M. C., Kuo, H. P., Zhu, L., Schneidawind, D., Duque-Afonso, J., Weng, Z., and Cleary, M. L. (2015) The H3K4-Methyl Epigenome Regulates Leukemia Stem Cell Oncogenic Potential. Cancer Cell 28, 198-209

19. Dou, Y., and Hess, J. L. (2008) Mechanisms of transcriptional regulation by MLL and its disruption in acute leukemia. Int J Hematol 87, 10-18

20. Dalgliesh, G. L., Furge, K., Greenman, C., Chen, L., Bignell, G., Butler, A., Davies, H., Edkins, S., Hardy, C., Latimer, C., Teague, J., Andrews, J., Barthorpe, S., Beare, D., Buck, G., Campbell, P. J., Forbes, S., Jia, M., Jones, D., Knott, H., Kok, C. Y., Lau, K. W., Leroy, C., Lin, M. L., McBride, D. J., Maddison, M., Maguire, S., McLay, K., Menzies, A., Mironenko, T., Mulderrig, L., Mudie, L., O'Meara, S., Pleasance, E., Rajasingham, A., Shepherd, R., Smith, R., Stebbings, L., Stephens, P., Tang, G., Tarpey, P. S., Turrell, K., Dykema, K. J., Khoo, S. K., Petillo, D., Wondergem, B., Anema, J., Kahnoski, R. J., Teh, B. T., Stratton, M. R., and Futreal, P. A. (2010) Systematic sequencing of renal carcinoma reveals inactivation of histone modifying genes. Nature 463, 360-363

21. Morin, R. D., Mendez-Lago, M., Mungall, A. J., Goya, R., Mungall, K. L., Corbett, R. D., Johnson, N. A., Severson, T. M., Chiu, R., Field, M., Jackman, S., Krzywinski, M., Scott, D. W., Trinh, D. L., Tamura-Wells, J., Li, S., Firme, M. R., Rogic, S., Griffith, M., Chan, S., Yakovenko, O., Meyer, I. M., Zhao, E. Y., Smailus, D., Moksa, M., Chittaranjan, S., Rimsza, L., Brooks-Wilson, A., Spinelli, J. J., Ben-Neriah, S., Meissner, B., Woolcock, B., Boyle, M., McDonald, H., Tam, A., Zhao, Y., Delaney, A., Zeng, T., Tse, K., Butterfield, Y., Birol, I., Holt, R., Schein, J., Horsman, D. E., Moore, R., Jones, S. J., Connors, J. M., Hirst, M., Gascoyne, R. D., and Marra, M. A. (2011) Frequent mutation of histone-modifying genes in non-Hodgkin lymphoma. Nature 476, 298-303

22. Parsons, D. W., Li, M., Zhang, X., Jones, S., Leary, R. J., Lin, J. C., Boca, S. M., Carter, H., Samayoa, J., Bettegowda, C., Gallia, G. L., Jallo, G. I., Binder, Z. A., Nikolsky, Y., Hartigan, J., Smith, D. R., Gerhard, D. S., Fults, D. W., VandenBerg, S., Berger, M. S., Marie, S. K., Shinjo, S. M., Clara, C., Phillips, P. C., Minturn, J. E., Biegel, J. A., Judkins, A. R., Resnick, A. C., Storm, P. B., Curran, T., He, Y., Rasheed, B. A., Friedman, H. S., Keir, S. T., McLendon, R., Northcott, P. A., Taylor, M. D., Burger, P. C., Riggins, G. J., Karchin, R., Parmigiani, G., Bigner, D. D., Yan, H., Papadopoulos, N., Vogelstein, B., Kinzler, K. W., and Velculescu, V. E. (2011) The genetic landscape of the childhood cancer medulloblastoma. Science 331, 435-439 
23. Pasqualucci, L., Trifonov, V., Fabbri, G., Ma, J., Rossi, D., Chiarenza, A., Wells, V. A., Grunn, A., Messina, M., Elliot, O., Chan, J., Bhagat, G., Chadburn, A., Gaidano, G., Mullighan, C. G., Rabadan, R., and Dalla-Favera, R. (2011) Analysis of the coding genome of diffuse large B-cell lymphoma. Nat Genet 43, 830-837

24. Grasso, C. S., Wu, Y. M., Robinson, D. R., Cao, X., Dhanasekaran, S. M., Khan, A. P., Quist, M. J., Jing, X., Lonigro, R. J., Brenner, J. C., Asangani, I. A., Ateeq, B., Chun, S. Y., Siddiqui, J., Sam, L., Anstett, M., Mehra, R., Prensner, J. R., Palanisamy, N., Ryslik, G. A., Vandin, F., Raphael, B. J., Kunju, L. P., Rhodes, D. R., Pienta, K. J., Chinnaiyan, A. M., and Tomlins, S. A. (2012) The mutational landscape of lethal castration-resistant prostate cancer. Nature 487, 239-243

25. Jones, W. D., Dafou, D., McEntagart, M., Woollard, W. J., Elmslie, F. V., Holder-Espinasse, M., Irving, M., Saggar, A. K., Smithson, S., Trembath, R. C., Deshpande, C., and Simpson, M. A. (2012) De novo mutations in MLL cause Wiedemann-Steiner syndrome. American journal of human genetics 91 , 358-364

26. Shilatifard, A. (2012) The COMPASS Family of Histone H3K4 Methylases: Mechanisms of Regulation in Development and Disease Pathogenesis. Annu Rev Biochem 81, 65-95

27. Bogershausen, N., and Wollnik, B. (2013) Unmasking Kabuki syndrome. Clinical genetics 83, 201-211

28. Flavahan, W. A., Gaskell, E., and Bernstein, B. E. (2017) Epigenetic plasticity and the hallmarks of cancer. Science $\mathbf{3 5 7}$

29. Ziemin-van der Poel, S., McCabe, N. R., Gill, H. J., Espinosa, R., III, Patel, Y., Harden, A., Rubinelli, P., Smith, S. D., LeBeau, M. M., Rowley, J. D., and et al. (1991) Identification of a gene, MLL, that spans the breakpoint in 11q23 translocations associated with human leukemias. Proc Natl Acad Sci U S A 88, 10735-10739

30. Nakamura, T., Mori, T., Tada, S., Krajewski, W., Rozovskaia, T., Wassell, R., Dubois, G., Mazo, A., Croce, C. M., and Canaani, E. (2002) ALL-1 is a histone methyltransferase that assembles a supercomplex of proteins involved in transcriptional regulation. Mol Cell 10, 1119-1128

31. Dou, Y., Milne, T. A., Tackett, A. J., Smith, E. R., Fukuda, A., Wysocka, J., Allis, C. D., Chait, B. T., Hess, J. L., and Roeder, R. G. (2005) Physical association and coordinate function of the H3 K4 methyltransferase MLL1 and the H4 K16 acetyltransferase MOF. Cell 121, 873885

32. Yokoyama, A., Wang, Z., Wysocka, J., Sanyal, M., Aufiero, D. J., Kitabayashi, I., Herr, W., and Cleary, M. L. (2004) Leukemia proto-oncoprotein MLL forms a SET1-like histone methyltransferase complex with menin to regulate Hox gene expression. Mol Cell Biol 24, 5639-5649

33. Wysocka, J., Myers, M. P., Laherty, C. D., Eisenman, R. N., and Herr, W. (2003) Human Sin3 deacetylase and trithorax-related Set1/Ash2 histone H3-K4 methyltransferase are tethered together selectively by the cell-proliferation factor HCF-1. Genes Dev 17, 896911

34. Dou, Y., Milne, T. A., Ruthenburg, A. J., Lee, S., Lee, J. W., Verdine, G. L., Allis, C. D., and Roeder, R. G. (2006) Regulation of MLL1 H3K4 methyltransferase activity by its core components. Nat Struct Mol Biol 13, 713-719 
35. Patel, A., Dharmarajan, V., and Cosgrove, M. S. (2008) Structure of WDR5 bound to Mixed Lineage Leukemia Protein-1 peptide. J Biol Chem 283, 32158-32161

36. Patel, A., Dharmarajan, V., Vought, V. E., and Cosgrove, M. S. (2009) On the mechanism of multiple lysine methylation by the human mixed lineage leukemia protein-1 (MLL1) core complex. J Biol Chem 284, 24242-24256

37. Patel, A., Vought, V., Dharmarajan, V., and Cosgrove, M. S. (2008) A conserved arginine containing motif crucial for the assembly and enzymatic activity of the Mixed Lineage Leukemia protein-1 core complex. J Biol Chem 283, 32162-32175

38. Roguev, A., Schaft, D., Shevchenko, A., Pijnappel, W. W., Wilm, M., Aasland, R., and Stewart, A. F. (2001) The Saccharomyces cerevisiae Set1 complex includes an Ash2 homologue and methylates histone 3 lysine 4. Embo J 20, 7137-7148

39. Southall, S. M., Wong, P. S., Odho, Z., Roe, S. M., and Wilson, J. R. (2009) Structural basis for the requirement of additional factors for MLL1 SET domain activity and recognition of epigenetic marks. Mol Cell 33, 181-191

40. Scacheri, P. C., Davis, S., Odom, D. T., Crawford, G. E., Perkins, S., Halawi, M. J., Agarwal, S. K., Marx, S. J., Spiegel, A. M., Meltzer, P. S., and Collins, F. S. (2006) Genome-Wide Analysis of Menin Binding Provides Insights into MEN1 Tumorigenesis. PLoS Genet 2, e51, 0406-0419

41. Shinsky, S. A., Hu, M., Vought, V. E., Ng, S. B., Bamshad, M. J., Shendure, J., and Cosgrove, M. S. (2014) A non-active site SET domain surface crucial for the interaction of MLL1 and the RbBP5/Ash2L heterodimer within MLL family core complexes. J. Mol. Biol. 426, 2283-2299

42. Grebien, F., Vedadi, M., Getlik, M., Giambruno, R., Grover, A., Avellino, R., Skucha, A., Vittori, S., Kuznetsova, E., Smil, D., Barsyte-Lovejoy, D., Li, F., Poda, G., Schapira, M., Wu, H., Dong, A., Senisterra, G., Stukalov, A., Huber, K. V., Schonegger, A., Marcellus, R., Bilban, M., Bock, C., Brown, P. J., Zuber, J., Bennett, K. L., Al-Awar, R., Delwel, R., Nerlov, C., Arrowsmith, C. H., and Superti-Furga, G. (2015) Pharmacological targeting of the Wdr5-MLL interaction in C/EBPalpha N-terminal leukemia. Nat Chem Biol 11, 571-578

43. Zhu, J., Sammons, M. A., Donahue, G., Dou, Z., Vedadi, M., Getlik, M., Barsyte-Lovejoy, D., Al-awar, R., Katona, B. W., Shilatifard, A., Huang, J., Hua, X., Arrowsmith, C. H., and Berger, S. L. (2015) Gain-of-function p53 mutants co-opt chromatin pathways to drive cancer growth. Nature 525, 206-211

44. Cao, F., Townsend, E. C., Karatas, H., Xu, J., Li, L., Lee, S., Liu, L., Chen, Y., Ouillette, P., Zhu, J., Hess, J. L., Atadja, P., Lei, M., Qin, Z. S., Malek, S., Wang, S., and Dou, Y. (2014) Targeting MLL1 H3K4 methyltransferase activity in mixed-lineage leukemia. Mol Cell 53, 247-261

45. Song, J. J., and Kingston, R. E. (2008) WDR5 interacts with mixed lineage leukemia (MLL) protein via the histone H3-binding pocket. J Biol Chem 283, 35258-35264

46. Avdic, V., Zhang, P., Lanouette, S., Groulx, A., Tremblay, V., Brunzelle, J., and Couture, J. F. Structural and biochemical insights into MLL1 core complex assembly. Structure 19, 101-108

47. Odho, Z., Southall, S. M., and Wilson, J. R. Characterization of a novel WDR5-binding site that recruits RbBP5 through a conserved motif to enhance methylation of histone H3 lysine 4 by mixed lineage leukemia protein-1. J Biol Chem 285, 32967-32976 
1002

1003

1004

1005

1006

1007

1008

1009

1010

1011

1012

1013

1014

1015

1016

1017

1018

1019

1020

1021

1022

1023

1024

48. South, P. F., Fingerman, I. M., Mersman, D. P., Du, H. N., and Briggs, S. D. (2010) A conserved interaction between the SDI domain of Bre2 and the Dpy-30 domain of Sdc1 is required for histone methylation and gene expression. J Biol Chem 285, 595-607

49. Cho, Y. W., Hong, T., Hong, S., Guo, H., Yu, H., Kim, D., Guszczynski, T., Dressler, G. R., Copeland, T. D., Kalkum, M., and Ge, K. (2007) PTIP associates with MLL3- and MLL4containing histone H3 lysine 4 methyltransferase complex. J Biol Chem 282, 2039520406

50. Qu, Q., Takahashi, Y. H., Yang, Y., Hu, H., Zhang, Y., Brunzelle, J. S., Couture, J. F., Shilatifard, A., and Skiniotis, G. (2018) Structure and Conformational Dynamics of a COMPASS Histone H3K4 Methyltransferase Complex. Cell 174, 1117-1126 e1112

51. Hsu, P. L., Li, H., Lau, H. T., Leonen, C., Dhall, A., Ong, S. E., Chatterjee, C., and Zheng, N. (2018) Crystal Structure of the COMPASS H3K4 Methyltransferase Catalytic Module. Cell 174, 1106-1116 e1109

52. Takahashi, Y. H., Westfield, G. H., Oleskie, A. N., Trievel, R. C., Shilatifard, A., and Skiniotis, G. (2011) Structural analysis of the core COMPASS family of histone H3K4 methylases from yeast to human. Proc Natl Acad Sci U S A 108, 20526-20531

53. Li, Y., Han, J., Zhang, Y., Cao, F., Liu, Z., Li, S., Wu, J., Hu, C., Wang, Y., Shuai, J., Chen, J., Cao, L., Li, D., Shi, P., Tian, C., Zhang, J., Dou, Y., Li, G., Chen, Y., and Lei, M. (2016) Structural basis for activity regulation of MLL family methyltransferases. Nature 530, 447-452

54. Lebowitz, J., Lewis, M. S., and Schuck, P. (2002) Modern analytical ultracentrifugation in protein science: a tutorial review. Protein science : a publication of the Protein Society 11, 2067-2079

55. Schuck, P. (2013) Analytical Ultracentrifugation as a Tool for Studying Protein Interactions. Biophys Rev 5, 159-171

56. Schuck, P. (2000) Size-distribution analysis of macromolecules by sedimentation velocity ultracentrifugation and lamm equation modeling. Biophys J 78, 1606-1619

57. Schuck, P. (2005) Diffusion-deconvoluted sedimentation coefficient distributions for the analysis of interacting and non-interacting protein mixtures. in Analytical Ultracentrifugation: Techniques and Methods (Scott, D. J., Harding, S. E., and Rowe, A. J. eds.), Royal Society of Chemistry, Cambridge, UK. pp 26-49

58. Schuck, P. (2003) On the analysis of protein self-association by sedimentation velocity analytical ultracentrifugation. Anal Biochem 320, 104-124

59. Dam, J., Velikovsky, C. A., Mariuzza, R. A., Urbanke, C., and Schuck, P. (2005) Sedimentation velocity analysis of heterogeneous protein-protein interactions: Lamm equation modeling and sedimentation coefficient distributions c(s). Biophys J 89, 619634

60. Brown, P. H., Balbo, A., and Schuck, P. (2007) Using prior knowledge in the determination of macromolecular size-distributions by analytical ultracentrifugation. Biomacromolecules 8, 2011-2024

61. Johnson, K. A., Simpson, Z. B., and Blom, T. (2009) Global kinetic explorer: a new computer program for dynamic simulation and fitting of kinetic data. Anal Biochem 387, 20-29 
1025

1026

1027

1028

1029

1030

1031

1032

1033

1034

1035

1036

1037

1038

1039

1040

1041

1042

1043

1044

1045

1046

1047

1048

1049

1050

1051

1052

1053

1054

1055

1056

1057

1058

1059

1060

1061

1062

1063

1064

1065

1066

1067

1068

62. Patel, A., Vought, V. E., Dharmarajan, V., and Cosgrove, M. S. (2011) A novel non-SET domain multi-subunit methyltransferase required for sequential nucleosomal histone H3 methylation by the mixed lineage leukemia protein-1 (MLL1) core complex. J Biol Chem 286, 3359-3369

63. Patel, A., Vought, V. E., Swatkoski, S., Viggiano, S., Howard, B., Dharmarajan, V., Monteith, K. E., Kupakuwana, G., Namitz, K. E., Shinsky, S. A., Cotter, R. J., and Cosgrove, M. S. (2013) Automethylation activities within the Mixed Lineage Leukemia-1 (MLL1) core complex reveal evidence supporting a "two-active site" model for multiple histone H3 lysine 4 methylation. J Biol Chem

64. Johnson, K. A., Simpson, Z. B., and Blom, T. (2009) FitSpace explorer: an algorithm to evaluate multidimensional parameter space in fitting kinetic data. Anal Biochem 387, 30-41

65. van Nuland, R., Smits, A. H., Pallaki, P., Jansen, P. W., Vermeulen, M., and Timmers, H. T. (2013) Quantitative dissection and stoichiometry determination of the human SET1/MLL histone methyltransferase complexes. Mol Cell Biol 33, 2067-2077

66. Yano, T., Nakamura, T., Blechman, J., Sorio, C., Dang, C. V., Geiger, B., and Canaani, E. (1997) Nuclear punctate distribution of ALL-1 is conferred by distinct elements at the $N$ terminus of the protein. Proc Natl Acad Sci U S A 94, 7286-7291

67. Rieder, D., Trajanoski, Z., and McNally, J. G. (2012) Transcription factories. Front Genet 3, 221

68. Papantonis, A., and Cook, P. R. (2013) Transcription factories: genome organization and gene regulation. Chem Rev 113, 8683-8705

69. Gibson, B. A., Doolittle, L. K., Schneider, M. W. G., Jensen, L. E., Gamarra, N., Henry, L., Gerlich, D. W., Redding, S., and Rosen, M. K. (2019) Organization of Chromatin by Intrinsic and Regulated Phase Separation. Cell 179, 470-484 e421

70. Mitrea, D. M., and Kriwacki, R. W. (2016) Phase separation in biology; functional organization of a higher order. Cell Commun Signal 14, 1

71. Dosztanyi, Z., Csizmok, V., Tompa, P., and Simon, I. (2005) The pairwise energy content estimated from amino acid composition discriminates between folded and intrinsically unstructured proteins. J Mol Biol 347, 827-839

72. Vedadi, M., Blazer, L., Eram, M. S., Barsyte-Lovejoy, D., Arrowsmith, C. H., and Hajian, T. (2017) Targeting human SET1/MLL family of proteins. Protein science : a publication of the Protein Society 26, 662-676

73. Larson, A. G., Elnatan, D., Keenen, M. M., Trnka, M. J., Johnston, J. B., Burlingame, A. L., Agard, D. A., Redding, S., and Narlikar, G. J. (2017) Liquid droplet formation by HP1alpha suggests a role for phase separation in heterochromatin. Nature 547, 236-240

74. Dam, J., and Schuck, P. (2004) Calculating sedimentation coefficient distributions by direct modeling of sedimentation velocity concentration profiles. Methods Enzymol 384, 185-212

75. Brown, P. H., and Schuck, P. (2006) Macromolecular size-and-shape distributions by sedimentation velocity analytical ultracentrifugation. Biophys J 90, 4651-4661

76. Chaton, C. T., and Herr, A. B. (2015) Elucidating Complicated Assembling Systems in Biology Using Size-and-Shape Analysis of Sedimentation Velocity Data. Methods Enzymol $562,187-204$ 
1069

1070

1071

1072

1073

1074

1075

1076

1077

1078

1079

1080

1081

1082

1083

1084

1085

1086

1087

1088

1089

1090

1091

1092

1093

1094

1095

1096

1097

1098

1099

1100

1101

1102

1103

1104

1105

1106

1107

1108

1109

1110

1111

1112

77. Banani, S. F., Lee, H. O., Hyman, A. A., and Rosen, M. K. (2017) Biomolecular condensates: organizers of cellular biochemistry. Nat Rev Mol Cell Biol 18, 285-298

78. Boehning, M., Dugast-Darzacq, C., Rankovic, M., Hansen, A. S., Yu, T., Marie-Nelly, H., McSwiggen, D. T., Kokic, G., Dailey, G. M., Cramer, P., Darzacq, X., and Zweckstetter, M. (2018) RNA polymerase II clustering through carboxy-terminal domain phase separation. Nat Struct Mol Biol 25, 833-840

79. Strulson, C. A., Molden, R. C., Keating, C. D., and Bevilacqua, P. C. (2012) RNA catalysis through compartmentalization. Nat Chem 4, 941-946

80. Neilsen, B. K., Chakraborty, B., McCall, J. L., Frodyma, D. E., Sleightholm, R. L., Fisher, K. W., and Lewis, R. E. (2018) WDR5 supports colon cancer cells by promoting methylation of H3K4 and suppressing DNA damage. BMC cancer 18, 673

81. Alicea-Velazquez, N. L., Shinsky, S. A., Loh, D. M., Lee, J. H., Skalnik, D. G., and Cosgrove, M. S. (2016) Targeted Disruption of the Interaction between WD-40 Repeat Protein 5 (WDR5) and Mixed Lineage Leukemia (MLL)/SET1 Family Proteins Specifically Inhibits MLL1 and SETd1A Methyltransferase Complexes. J Biol Chem 291, 22357-22372

82. Lee, J. H., Tate, C. M., You, J. S., and Skalnik, D. G. (2007) Identification and characterization of the human Set1B histone H3-Lys4 methyltransferase complex. J Biol Chem 282, 13419-13428

83. Tariq, M., Nussbaumer, U., Chen, Y., Beisel, C., and Paro, R. (2009) Trithorax requires Hsp90 for maintenance of active chromatin at sites of gene expression. Proc Natl Acad Sci U S A 106, 1157-1162

84. Shinsky, S. A., Monteith, K. E., Viggiano, S., and Cosgrove, M. S. (2015) Biochemical reconstitution and phylogenetic comparison of human SET1 family core complexes involved in histone methylation. J Biol Chem 290, 6361-6375

85. Kim, J. Y., Banerjee, T., Vinckevicius, A., Luo, Q., Parker, J. B., Baker, M. R., Radhakrishnan, I., Wei, J. J., Barish, G. D., and Chakravarti, D. (2014) A role for WDR5 in integrating threonine 11 phosphorylation to lysine 4 methylation on histone $\mathrm{H} 3$ during androgen signaling and in prostate cancer. Mol Cell 54, 613-625

86. Chen, X., Xie, W., Gu, P., Cai, Q., Wang, B., Xie, Y., Dong, W., He, W., Zhong, G., Lin, T., and Huang, J. (2015) Upregulated WDR5 promotes proliferation, self-renewal and chemoresistance in bladder cancer via mediating H3K4 trimethylation. Sci Rep 5, 8293

87. Ge, Z., Song, E. J., Kawasawa, Y. I., Li, J., Dovat, S., and Song, C. (2016) WDR5 high expression and its effect on tumorigenesis in leukemia. Oncotarget 7, 37740-37754

88. Dai, X., Guo, W., Zhan, C., Liu, X., Bai, Z., and Yang, Y. (2015) WDR5 Expression Is Prognostic of Breast Cancer Outcome. PLoS One 10, e0124964

89. Cui, Z., Li, H., Liang, F., Mu, C., Mu, Y., Zhang, X., and Liu, J. (2018) Effect of high WDR5 expression on the hepatocellular carcinoma prognosis. Oncol Lett 15, 7864-7870

90. Zhang, P., Chaturvedi, C. P., Tremblay, V., Cramet, M., Brunzelle, J. S., Skiniotis, G., Brand, M., Shilatifard, A., and Couture, J. F. (2015) A phosphorylation switch on RbBP5 regulates histone H3 Lys4 methylation. Genes Dev 29, 123-128

91. Wang, K. C., Yang, Y. W., Liu, B., Sanyal, A., Corces-Zimmerman, R., Chen, Y., Lajoie, B. R., Protacio, A., Flynn, R. A., Gupta, R. A., Wysocka, J., Lei, M., Dekker, J., Helms, J. A., and Chang, H. Y. (2011) A long noncoding RNA maintains active chromatin to coordinate homeotic gene expression. Nature 472, 120-124 
92. Li, P., Banjade, S., Cheng, H. C., Kim, S., Chen, B., Guo, L., Llaguno, M., Hollingsworth, J. V., King, D. S., Banani, S. F., Russo, P. S., Jiang, Q. X., Nixon, B. T., and Rosen, M. K. (2012) Phase transitions in the assembly of multivalent signalling proteins. Nature 483, 336-340

93. Koga, S., Williams, D. S., Perriman, A. W., and Mann, S. (2011) Peptide-nucleotide microdroplets as a step towards a membrane-free protocell model. Nat Chem 3, 720724

94. Dhar, A., Samiotakis, A., Ebbinghaus, S., Nienhaus, L., Homouz, D., Gruebele, M., and Cheung, M. S. (2010) Structure, function, and folding of phosphoglycerate kinase are strongly perturbed by macromolecular crowding. Proc Natl Acad Sci U S A 107, 1758617591

95. Pozdnyakova, I., and Wittung-Stafshede, P. (2010) Non-linear effects of macromolecular crowding on enzymatic activity of multi-copper oxidase. Biochim Biophys Acta 1804, 740-744

96. Aumiller, W. M., Jr., Davis, B. W., Hatzakis, E., and Keating, C. D. (2014) Interactions of macromolecular crowding agents and cosolutes with small-molecule substrates: effect on horseradish peroxidase activity with two different substrates. J Phys Chem B 118, 10624-10632

97. Pastor, I., Vilaseca, E., Madurga, S., Garces, J. L., Cascante, M., and Mas, F. (2011) Effect of crowding by dextrans on the hydrolysis of N-Succinyl-L-phenyl-Ala-p-nitroanilide catalyzed by alpha-chymotrypsin. J Phys Chem B 115, 1115-1121

98. Sanulli, S., Trnka, M. J., Dharmarajan, V., Tibble, R. W., Pascal, B. D., Burlingame, A. L., Griffin, P. R., Gross, J. D., and Narlikar, G. J. (2019) HP1 reshapes nucleosome core to promote heterochromatin phase separation. Nature

99. Wang, L., Gao, Y., Zheng, X., Liu, C., Dong, S., Li, R., Zhang, G., Wei, Y., Qu, H., Li, Y., Allis, C. D., Li, G., Li, H., and Li, P. (2019) Histone Modifications Regulate Chromatin Compartmentalization by Contributing to a Phase Separation Mechanism. Mol Cell

100. Plys, A. J., Davis, C. P., Kim, J., Rizki, G., Keenen, M. M., Marr, S. K., and Kingston, R. E. (2019) Phase separation of Polycomb-repressive complex 1 is governed by a charged disordered region of CBX2. Genes Dev 33, 799-813

101. Shinsky, S. A., and Cosgrove, M. S. (2015) Unique Role of the WD-40 Repeat Protein 5 (WDR5) Subunit within the Mixed Lineage Leukemia 3 (MLL3) Histone Methyltransferase Complex. J Biol Chem 290, 25819-25833

102. Zhang, P., Lee, H., Brunzelle, J. S., and Couture, J. F. (2012) The plasticity of WDR5 peptide-binding cleft enables the binding of the SET1 family of histone methyltransferases. Nucleic Acids Res 40, 4237-4246

103. Jackson, D. A., Hassan, A. B., Errington, R. J., and Cook, P. R. (1993) Visualization of focal sites of transcription within human nuclei. EMBO J 12, 1059-1065

104. Wansink, D. G., Schul, W., van der Kraan, I., van Steensel, B., van Driel, R., and de Jong, L. (1993) Fluorescent labeling of nascent RNA reveals transcription by RNA polymerase II in domains scattered throughout the nucleus. The Journal of cell biology 122, 283-293

105. Melnik, S., Deng, B., Papantonis, A., Baboo, S., Carr, I. M., and Cook, P. R. (2011) The proteomes of transcription factories containing RNA polymerases I, II or III. Nat Methods 8, 963-968 
106. Vernon, R. M., Chong, P. A., Tsang, B., Kim, T. H., Bah, A., Farber, P., Lin, H., and FormanKay, J. D. (2018) Pi-Pi contacts are an overlooked protein feature relevant to phase separation. eLife 7

107. Bolognesi, B., Lorenzo Gotor, N., Dhar, R., Cirillo, D., Baldrighi, M., Tartaglia, G. G., and Lehner, B. (2016) A Concentration-Dependent Liquid Phase Separation Can Cause Toxicity upon Increased Protein Expression. Cell reports 16, 222-231

108. Guenther, M. G., Jenner, R. G., Chevalier, B., Nakamura, T., Croce, C. M., Canaani, E., and Young, R. A. (2005) Global and Hox-specific roles for the MLL1 methyltransferase. Proc Natl Acad Sci U S A 102, 8603-8608

109. Milne, T. A., Dou, Y., Martin, M. E., Brock, H. W., Roeder, R. G., and Hess, J. L. (2005) MLL associates specifically with a subset of transcriptionally active target genes. Proc NatI Acad Sci U S A 102, 14765-14770

110. Perham, R. N. (2000) Swinging arms and swinging domains in multifunctional enzymes: catalytic machines for multistep reactions. Annu Rev Biochem 69, 961-1004

111. UniProt, C. (2019) UniProt: a worldwide hub of protein knowledge. Nucleic Acids Res 47, D506-D515

112. Tan, S., Kern, R. C., and Selleck, W. (2005) The pST44 polycistronic expression system for producing protein complexes in Escherichia coli. Protein Expr Purif 40, 385-395

113. Gasteiger, E., Hoogland, C., Gattiker, A., Duvaud, S. e., Wilkins, M. R., Appel, R. D., and Bairoch, A. (2005) Protein Identification and Analysis Tools on the ExPASy Server. in The Proteomics Protocols Handbook. pp 571-607

114. Laue, T. M., Shah, B., Ridgeway, T. M., and Pelletier, S. L. (1992) Computer-aided interpretation of analytical sedimentation data for proteins. in Analytical Ultracentrifugation in Biochemistry and Polymer Science (Harding, S. E., Rowe, A. J., and Horton, L. C. eds.), Royal Society of Chemistry, Cambridge. pp 90-125

115. Brautigam, C. A. (2015) Calculations and Publication-Quality Illustrations for Analytical Ultracentrifugation Data. Methods Enzymol 562, 109-133

116. Chaturvedi, S. K., Ma, J., Zhao, H., and Schuck, P. (2017) Use of fluorescence-detected sedimentation velocity to study high-affinity protein interactions. Nat Protoc 12, 17771791

117. Toseland, C. P. (2013) Fluorescent labeling and modification of proteins. J Chem Biol 6, 85-95 
Table 1: Summary of apparent dissociation constants for MLL1 core complex assembly at different temperatures*

\begin{tabular}{ccc}
\hline \hline $\begin{array}{c}\text { Temperature } \\
\left({ }^{\circ} \mathbf{C}\right)\end{array}$ & $\begin{array}{c}\mathbf{K}_{\boldsymbol{d}^{a p p}} \\
(\mathbf{n M})\end{array}$ & $\begin{array}{c}\text { Confidence inter } \\
(\mathbf{1 \sigma})\end{array}$ \\
\hline & & \\
$\mathbf{5}$ & 7 & $6-9$ \\
$\mathbf{1 0}$ & 7 & $5-11$ \\
$\mathbf{1 5}$ & 20 & $13-30$ \\
$\mathbf{2 0}$ & 30 & $22-39$ \\
$\mathbf{2 5}$ & 62 & $51-72$ \\
$\mathbf{3 0}$ & 290 & $204-417$ \\
$\mathbf{3 7}$ & 6200 & $4900-7900$
\end{tabular}

* Dissociation constants and error estimates were obtained from fitting $M W R A D_{2}$ concentration versus signal weight average sedimentation coefficient $\left(s_{w}\right)$ using the $A+B \leftrightharpoons A B$ hetero-association model in SEDPHAT (59).

Table 2. Pseudo-first order rate constants for H3K4 monomethylation $\left(k_{m e}\right)$ catalyzed by $\mathrm{MWRAD}_{2}$ at the indicated concentration and temperature ${ }^{*}$

\begin{tabular}{|c|c|c|c|c|c|c|c|}
\hline Temperature: & $5^{\circ} \mathrm{C}$ & $10^{\circ} \mathrm{C}$ & $15^{\circ} \mathrm{C}$ & $20^{\circ} \mathrm{C}$ & $25^{\circ} \mathrm{C}$ & $30^{\circ} \mathrm{C}$ & $37^{\circ} \mathrm{C}$ \\
\hline$\left[\mathrm{MWRAD}_{2}\right], \mu \mathrm{M}$ & $k_{m e 1}, \min ^{-1}$ & $k_{m e 1}, \min ^{-1}$ & $k_{m e 1}, m^{-1}$ & $k_{m e 1}, \min ^{-1}$ & $k_{m e 1}, \min ^{-1}$ & $k_{m e 1}, \min ^{-1}$ & $k_{m e 1}, m^{-1}$ \\
\hline 0.25 & $0.01 \pm 0.01$ & $0.03 \pm 0.02$ & $0.03 \pm 0.04$ & $0.03 \pm 0.03$ & $0.0 \pm 0.05$ & $N / A^{a}$ & N/A \\
\hline 0.5 & $0.06 \pm 0.01$ & $0.10 \pm 0.02$ & $0.15 \pm 0.03$ & $0.18 \pm 0.03$ & $0.11 \pm 0.05$ & $0.03 \pm 0.02$ & N/A \\
\hline 0.75 & $0.06 \pm 0.01$ & $0.16 \pm 0.02$ & $0.16 \pm 0.02$ & $0.24 \pm 0.02$ & $0.12 \pm 0.04$ & $0.07 \pm 0.05$ & $0.00 \pm 0.02$ \\
\hline 1.0 & $0.13 \pm 0.01$ & $0.19 \pm 0.04$ & $0.25 \pm 0.04$ & $0.29 \pm 0.04$ & $0.19 \pm 0.04$ & $0.18 \pm 0.04$ & $0.07 \pm$ N.D. ${ }^{b}$ \\
\hline 5.0 & $0.13 \pm 0.02$ & $0.26 \pm 0.04$ & $0.31 \pm 0.04$ & $0.32 \pm 0.04$ & $0.30 \pm 0.04$ & $0.28 \pm 0.04$ & $0.13 \pm 0.06$ \\
\hline
\end{tabular}

* Each is the rate constant +/- the Standard Error determined from duplicate measurements.

aN/A, Not applicable - no methylation observed under the indicated condition.

${ }^{b}$ N.D., error estimates are not defined. 
Table 3. Pseudo-first order rate constants for H3K4 dimethylation $\left(k_{m e 2}\right)$ catalyzed by $\mathrm{MWRAD}_{2}$ at the indicated concentration and temperature*

\begin{tabular}{|c|c|c|c|c|c|c|c|}
\hline Temperature: & $5^{\circ} \mathrm{C}$ & $10^{\circ} \mathrm{C}$ & $15^{\circ} \mathrm{C}$ & $20^{\circ} \mathrm{C}$ & $25^{\circ} \mathrm{C}$ & $30^{\circ} \mathrm{C}$ & $37^{\circ} \mathrm{C}$ \\
\hline [MWRAD2], $\mu \mathrm{M}$ & $k_{m e 2}, \min ^{-1}$ & $k_{m e 2}, \min ^{-1}$ & $k_{m e 2}, \min ^{-1}$ & $k_{m e 2}, \min ^{-1}$ & $k_{m e 2}, \min ^{-1}$ & $k_{m e 2}, \min ^{-1}$ & $k_{m e 2}, m_{i n}^{-1}$ \\
\hline 0.5 & $0.01 \pm 0.00$ & $0.01 \pm 0.01$ & $0.02 \pm 0.01$ & $0.03 \pm 0.01$ & $0.01 \pm 0.04$ & N/A & $\mathrm{N} / \mathrm{A}$ \\
\hline 0.75 & $0.01 \pm 0.00$ & $0.03 \pm 0.01$ & $0.04 \pm 0.01$ & $0.07 \pm 0.02$ & $0.03 \pm 0.02$ & $0.01 \pm 0.06$ & N/A \\
\hline 1.0 & $0.02 \pm 0.00$ & $0.05 \pm 0.02$ & $0.06 \pm 0.02$ & $0.09 \pm 0.03$ & $0.06 \pm 0.04$ & $0.04 \pm 0.01$ & $\mathrm{~N} / \mathrm{A}$ \\
\hline 5.0 & $0.03 \pm 0.01$ & $0.08 \pm 0.01$ & $0.09 \pm 0.01$ & $0.12 \pm 0.02$ & $0.12 \pm 0.02$ & $0.11 \pm 0.02$ & $0.09 \pm 0.06$ \\
\hline
\end{tabular}

* Each is the rate constant $+/$ - the Standard Error determined from duplicate measurements.

aN/A, Not applicable - no methylation observed under the indicated condition.

Table 4. Pseudo-first order rate constants for $M W R A D_{2}$ irreversible inactivation $\left(k_{\text {inact }}\right)$

\begin{tabular}{|c|c|c|c|c|c|c|c|}
\hline Temperature: & $5^{\circ} \mathrm{C}$ & $10^{\circ} \mathrm{C}$ & $15^{\circ} \mathrm{C}$ & $20^{\circ} \mathrm{C}$ & $25^{\circ} \mathrm{C}$ & $30^{\circ} \mathrm{C}$ & $37^{\circ} \mathrm{C}$ \\
\hline$\left[\mathrm{MWRAD}_{2}\right], \mu \mathrm{M}$ & $k_{\text {inact, }} \min ^{-1}$ & kinact, $\min ^{-1}$ & $k_{\text {inact }} \min ^{-1}$ & $k_{\text {inact, }} \min ^{-1}$ & $k_{\text {inact, }} \min ^{-1}$ & $k_{\text {inact }} \min ^{-1}$ & $k_{\text {inact, }} \min ^{-1}$ \\
\hline 0.25 & $0.01 \pm 0.02$ & $0.02 \pm 0.02$ & $0.04 \pm 0.08$ & $0.05 \pm 0.05$ & $0.08 \pm 1.07$ & $>1700^{b}$ & $>2000^{\mathrm{b}}$ \\
\hline 0.5 & $0.01 \pm 0.01$ & $0.002 \pm 0.01$ & $0.01 \pm 0.02$ & $0.02 \pm 0.01$ & $0.06 \pm 0.04$ & $0.09 \pm 0.07$ & $>390^{b}$ \\
\hline 0.75 & $0.00 \pm 0.01$ & $0.009 \pm 0.01$ & $0.02 \pm 0.01$ & $0.03 \pm 0.01$ & $0.04 \pm 0.03$ & $0.09 \pm 0.08$ & $0.13 \pm 1.00$ \\
\hline 1.0 & $0.00 \pm$ N.D. ${ }^{a}$ & $0.01 \pm 0.02$ & $0.01 \pm 0.01$ & $0.04 \pm 0.02$ & $0.04 \pm 0.03$ & $0.07 \pm 0.03$ & $0.24 \pm 0.11$ \\
\hline 5.0 & $0.01 \pm 0.01$ & $0.05 \pm 0.02$ & $0.00 \pm 0.00$ & $0.09 \pm 0.02$ & $0.07 \pm 0.03$ & $0.07 \pm 0.02$ & $0.21 \pm 0.13$ \\
\hline
\end{tabular}

\footnotetext{
* Each is the rate constant $+/-$ the Standard Error determined from duplicate measurements.

a N.D., error estimates are not defined.

${ }^{\mathrm{b}} k_{\text {inact }}$ lower bound. In Kintek Explorer software, $k_{m e}$ was fixed to the value predicted by the Arrhenius equation at the indicated temperature and $k_{\text {inact }}$ was floated to estimate the lower bound required for the observed loss of activity.
} 
Table 5. Pseudo-first order rate constants for $5 \mu \mathrm{M} \mathrm{MWRAD}_{2}$ at $37^{\circ} \mathrm{C}$ in high $(200 \mathrm{mM})$ and low $(25 \mathrm{mM}) \mathrm{NaCl}$ reaction buffer $^{*}$

\begin{tabular}{|c|c|c|c|c|c|c|c|c|}
\hline \multirow[t]{2}{*}{ [MWRAD 2$], \mu M$} & \multicolumn{2}{|c|}{$\begin{array}{l}k_{1}\left(\mathrm{~min}^{-1}\right) \\
{[\mathrm{NaCl}], \mathrm{mM}}\end{array}$} & \multicolumn{2}{|c|}{$\begin{array}{l}k_{2}\left(\mathrm{~min}^{-1}\right) \\
{[\mathrm{NaCl}], \mathrm{mM}}\end{array}$} & \multicolumn{2}{|c|}{$\begin{array}{l}k_{3}\left(\mathrm{~min}^{-1}\right) \\
{[\mathrm{NaCl}], \mathrm{mM}}\end{array}$} & \multicolumn{2}{|c|}{$\begin{array}{c}k_{\text {inact }}\left(\mathrm{min}^{-1}\right) \\
{[\mathrm{NaCl}], \mathrm{mM}}\end{array}$} \\
\hline & 200 & 25 & 200 & 25 & 200 & 25 & 200 & 25 \\
\hline 0.25 & $\mathrm{~N} / \mathrm{A}^{\mathrm{a}}$ & $0.3(0.01)$ & $\mathrm{N} / \mathrm{A}$ & $\mathrm{N} / \mathrm{A}$ & $\mathrm{N} / \mathrm{A}$ & $N / A$ & $\mathrm{~N} / \mathrm{A}$ & 0.00 (N.D.) \\
\hline 0.5 & N/A & $1.4(0.10)$ & $\mathrm{N} / \mathrm{A}$ & $1.1(0.20)$ & $\mathrm{N} / \mathrm{A}$ & $N / A$ & $\mathrm{~N} / \mathrm{A}$ & 0.00 (N.D.) \\
\hline 0.75 & $0.00(0.02)^{c}$ & $1.5(0.10)$ & $\mathrm{N} / \mathrm{A}$ & $1.2(0.09)$ & $\mathrm{N} / \mathrm{A}$ & $N / A$ & $0.13(1.00)$ & 0.00 (N.D.) \\
\hline 1.0 & 0.07 (N.D. $\left.{ }^{b}\right)$ & $2.3(0.20)$ & $\mathrm{N} / \mathrm{A}$ & $1.9(0.10)$ & $\mathrm{N} / \mathrm{A}$ & $0.01(0.01)$ & $0.24(0.11)$ & 0.00 (N.D.) \\
\hline 5.0 & $0.13(0.06)$ & $8.1(1.80)$ & $0.09(0.06)$ & $4.5(0.30)$ & $\mathrm{N} / \mathrm{A}$ & 0.03 (N.D.) & $0.21(0.13)$ & 0.00 (N.D.) \\
\hline
\end{tabular}

* Each is the rate constant with Standard Error determined from duplicate measurements in parentheses.

aN/A, Not applicable - no methylation observed.

${ }^{b}$ N.D., error estimates are not defined.

${ }^{c}$ rates below $5 \times 10^{-3}$ were rounded to 0.00 . 
bioRxiv preprint doi: https://doi.org/10.1101/870667; this version posted December 10, 2019. The copyright holder for this preprint (which was not certified by peer review) is the author/funder, who has granted bioRxiv a license to display the preprint in perpetuity. It is made available

Figure 1 - Namitz, Tan and Cosgrove

A

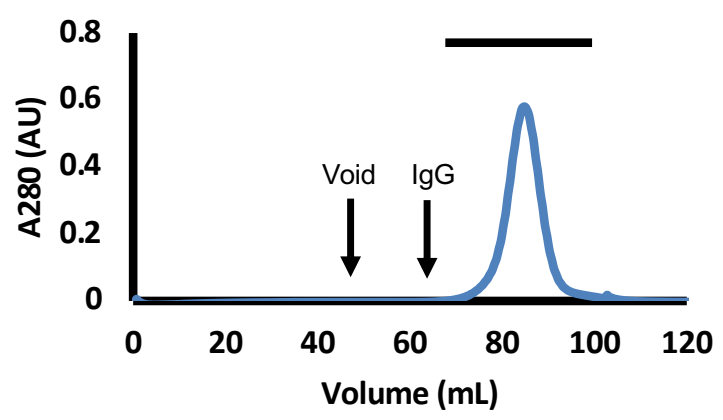

C

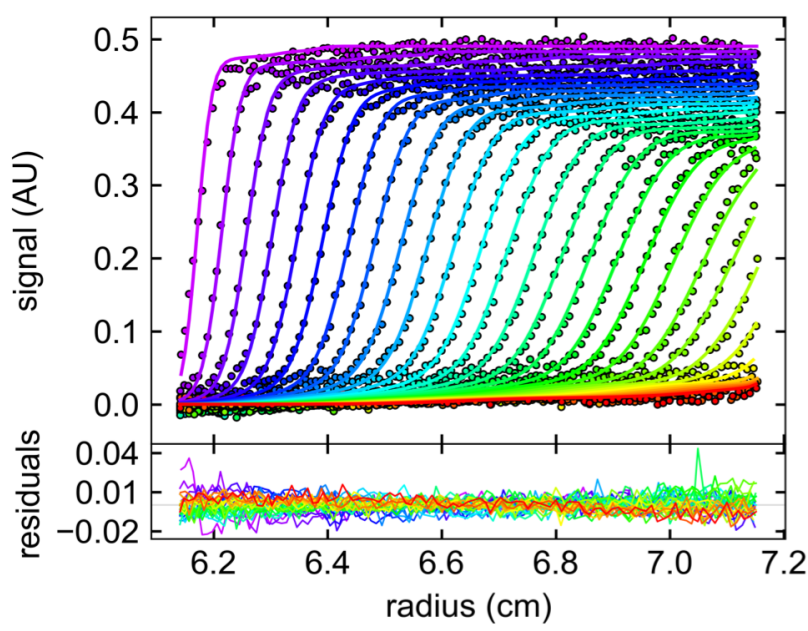

B

S I 112304566778910111213
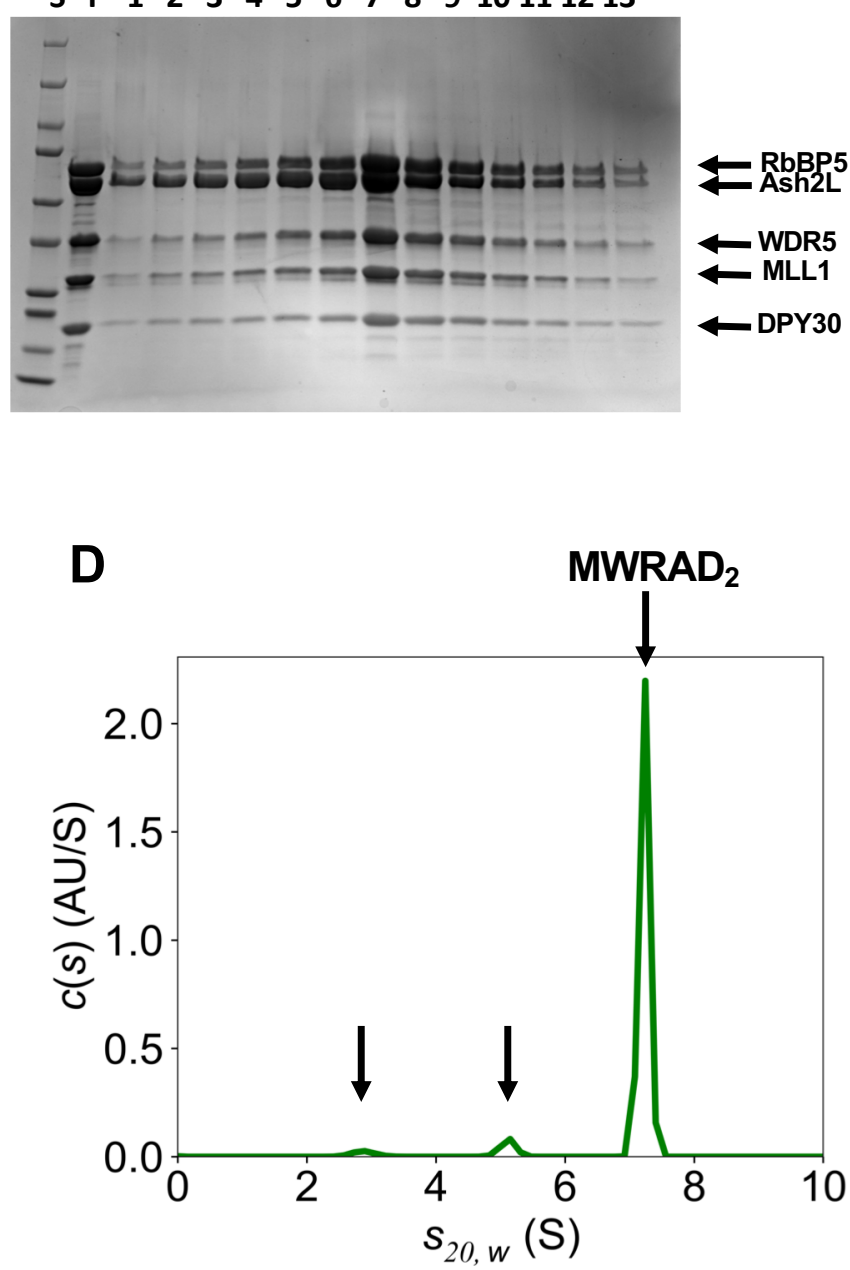

Figure 1: Purification and characterization of the MLL1 core complex. (A) Chromatogram of S200 SEC purified MWRAD ${ }_{2}$. The void volume and elution volume of $\lg G\left(\mathrm{M}_{\mathrm{r}} 158 \mathrm{kDa}\right)$ are indicated. The horizontal bar above the peak indicates fractions shown on the Coomassie stained SDS-PAGE gel in (B). (C) Upper Panel: SV-AUC run showing raw data (points) and fits using the continuous distribution $(c(s))$ method by the program SEDFIT (solid lines) (56). The lower panel shows the residuals derived from the fit. Shown is a typical run of $5 \mu \mathrm{M}$ $M W R A D_{2}$ taken at $5^{\circ} \mathrm{C}$. (D) Diffusion-deconvolved sedimentation coefficient distribution $(c(s))$ obtained using the fits to the raw data shown in (C). All profiles are shown with experimental $s^{*}$ values corrected to standard conditions at $20^{\circ} \mathrm{C}$ in water $\left(s_{20, w}(S)\right)$. The positions of $M W R A D_{2}$ and the two minor peaks are indicated with arrows. 
Figure 2 - Namitz, Tan and Cosgrove

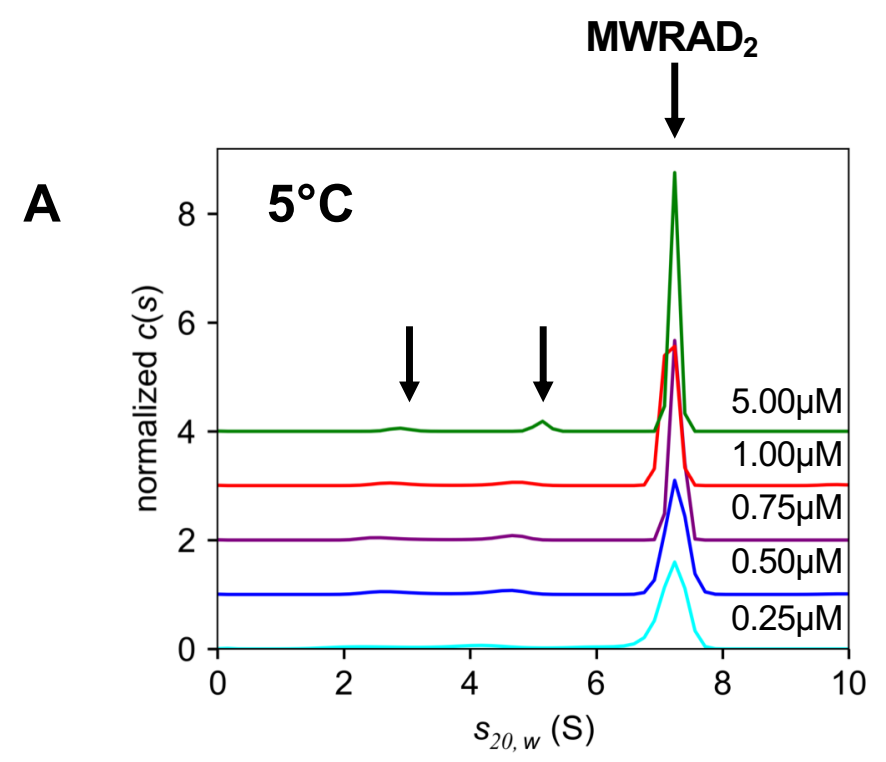

B

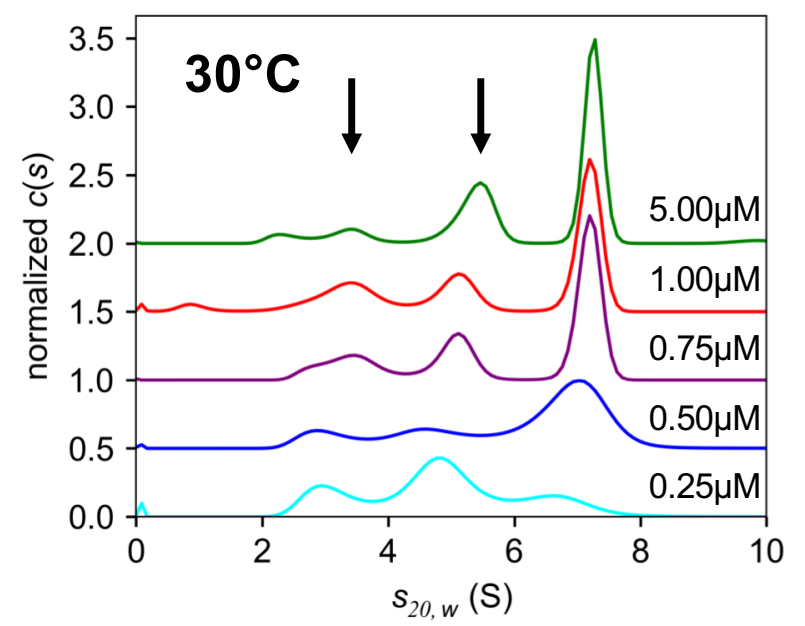

Figure 2: The holo-MLL1 core complex assembles from predominantly two sub-complexes. (A) $c(s)$ distributions of $\mathrm{MWRAD}_{2}$ at $5^{\circ} \mathrm{C}$ at five different concentrations: $0.25 \mu \mathrm{M}$ (cyan), $0.5 \mu \mathrm{M}$ (blue), $0.75 \mu \mathrm{M}$ (purple), $1.0 \mu \mathrm{M}$ (red) and $5.0 \mu \mathrm{M}$ (green). Each profile was normalized by total integrated area under the peaks. (B) The same as in (A), but at $30^{\circ} \mathrm{C}$. The unlabeled arrows in both $(A)$ and $(B)$ indicate the positions of the putative subcomplex peaks at the highest concentration. 
Figure 3 - Namitz, Tan and Cosgrove
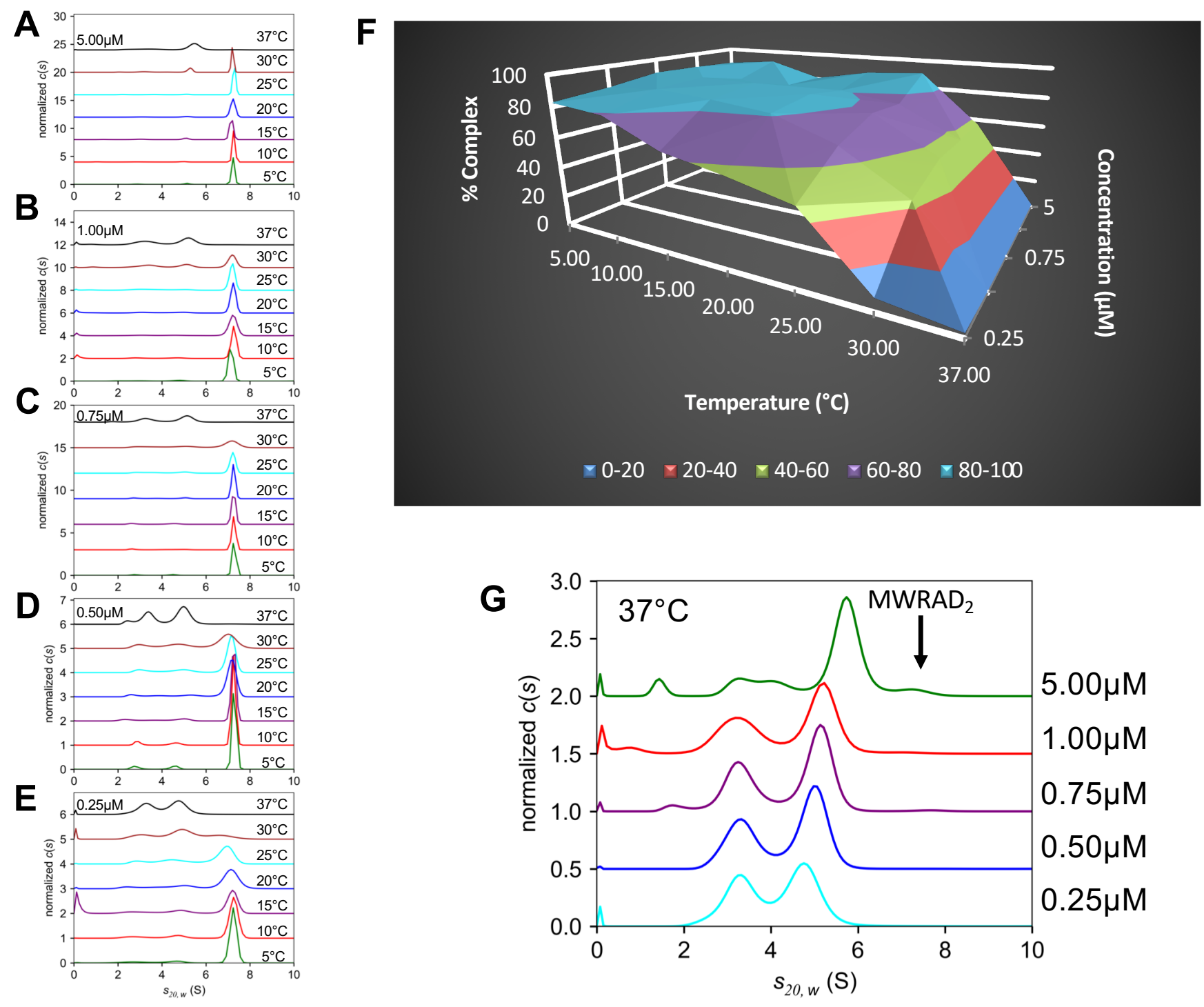

Figure 3: Temperature dependence of MLL1 core complex assembly. (A-E)

Representative $c(s)$ distributions of the MLL1 core complex at the indicated temperatures and loading concentrations. Each distribution was normalized for total integrated area. $(F)$ Surface plot summarizing the percentage of signal in SV-AUC experiments corresponding to the $S$ value of the MLL1 core complex as a function of temperature and concentration (see also Table S1). These values were obtained as described in Methods. (G) $c(s)$ distributions from five $M W R A D_{2}$ concentrations at $37^{\circ} \mathrm{C}$ normalized by total integrated area (note: each distribution corresponds to the black line from the respective concentration panel in $A-E$ ). The position of holo-MWRAD 2 at $7.2 S$ is indicated with the arrow. 
Figure 4 - Namitz, Tan and Cosgrove

A

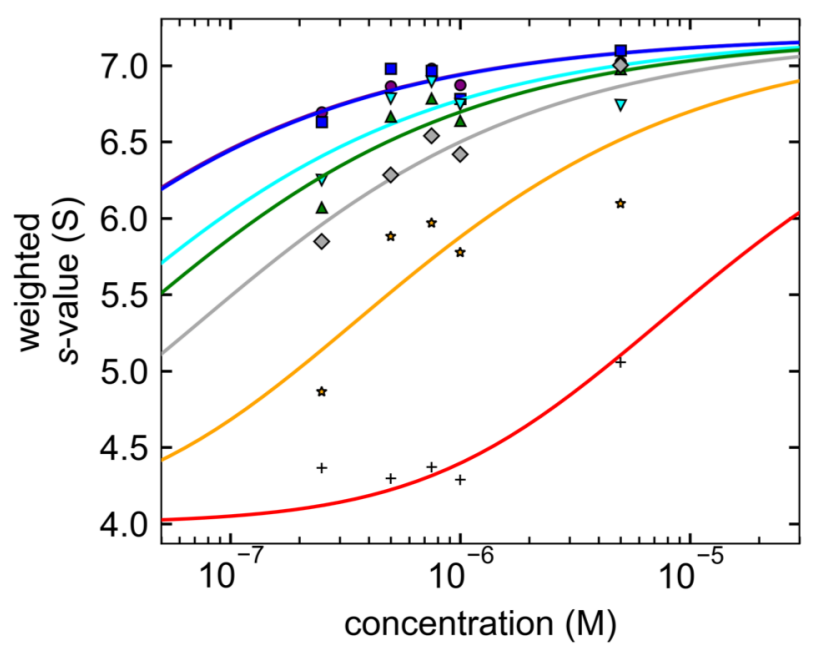

B

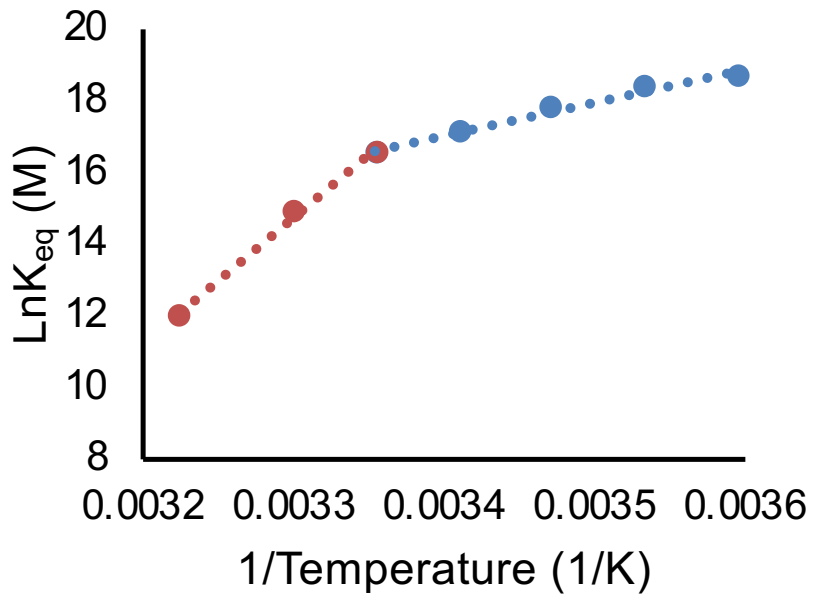

C

\begin{tabular}{|c|c|c|c|c|}
\hline Temp range & $\begin{array}{c}\Delta G \\
\left(25^{\circ} \mathrm{C}\right) \\
(\mathrm{kcal} / \mathrm{mol} \mathrm{K})\end{array}$ & $\begin{array}{c}\Delta \mathrm{H} \\
\left(25^{\circ} \mathrm{C}\right) \\
(\mathrm{kcal} / \mathrm{mol} \mathrm{K})\end{array}$ & $\begin{array}{c}\Delta \mathrm{S} \\
\left(25^{\circ} \mathrm{C}\right) \\
(\mathrm{kcal} / \mathrm{mol} \mathrm{K})\end{array}$ & $\begin{array}{l}\Delta H / \Delta S \\
\left(25^{\circ} \mathrm{C}\right)\end{array}$ \\
\hline $\operatorname{Low}\left(5-25^{\circ} \mathrm{C}\right)$ & -9.8 & -18 & -0.029 & 634 \\
\hline High $\left(25-37^{\circ} \mathrm{C}\right)$ & -9.9 & -70 & -0.202 & 347 \\
\hline
\end{tabular}

Figure 4: Thermodynamic characterization of MLL1 core complex assembly. (A) Signal-weighted $\left(s_{w}\right)$ isotherms of MWRAD ${ }_{2}$ were obtained for each temperature, plotted against loading concentrations and fit to an $\mathrm{A}+\mathrm{B} \leftrightharpoons \mathrm{AB}$ hetero-association model using SEDPHAT (114). The lines represent the fits for each isotherm, which were conducted at $5^{\circ} \mathrm{C}$ (blue), $10^{\circ} \mathrm{C}$ (purple), $15^{\circ} \mathrm{C}$ (cyan), $20^{\circ} \mathrm{C}$ (green), $25^{\circ} \mathrm{C}$ (grey), $30^{\circ} \mathrm{C}$ (orange) and $37^{\circ} \mathrm{C}$ (red). $K_{d}^{a p p}$ values are summarized in Table 1. (B) van't Hoff plot derived from the apparent $K_{e q}$ values. Linear regression was used to independently fit the data for the high temperature range $\left(\mathrm{red}, 25-37^{\circ} \mathrm{C}\right.$ ) and low temperature range (blue, $5-25^{\circ} \mathrm{C}$ ). (C) Summary of thermodynamic parameters for MLL1 core complex assembly under high and low temperature regimes derived from the van't Hoff analysis in (B). 
Figure 5 - Namitz, Tan and Cosgrove
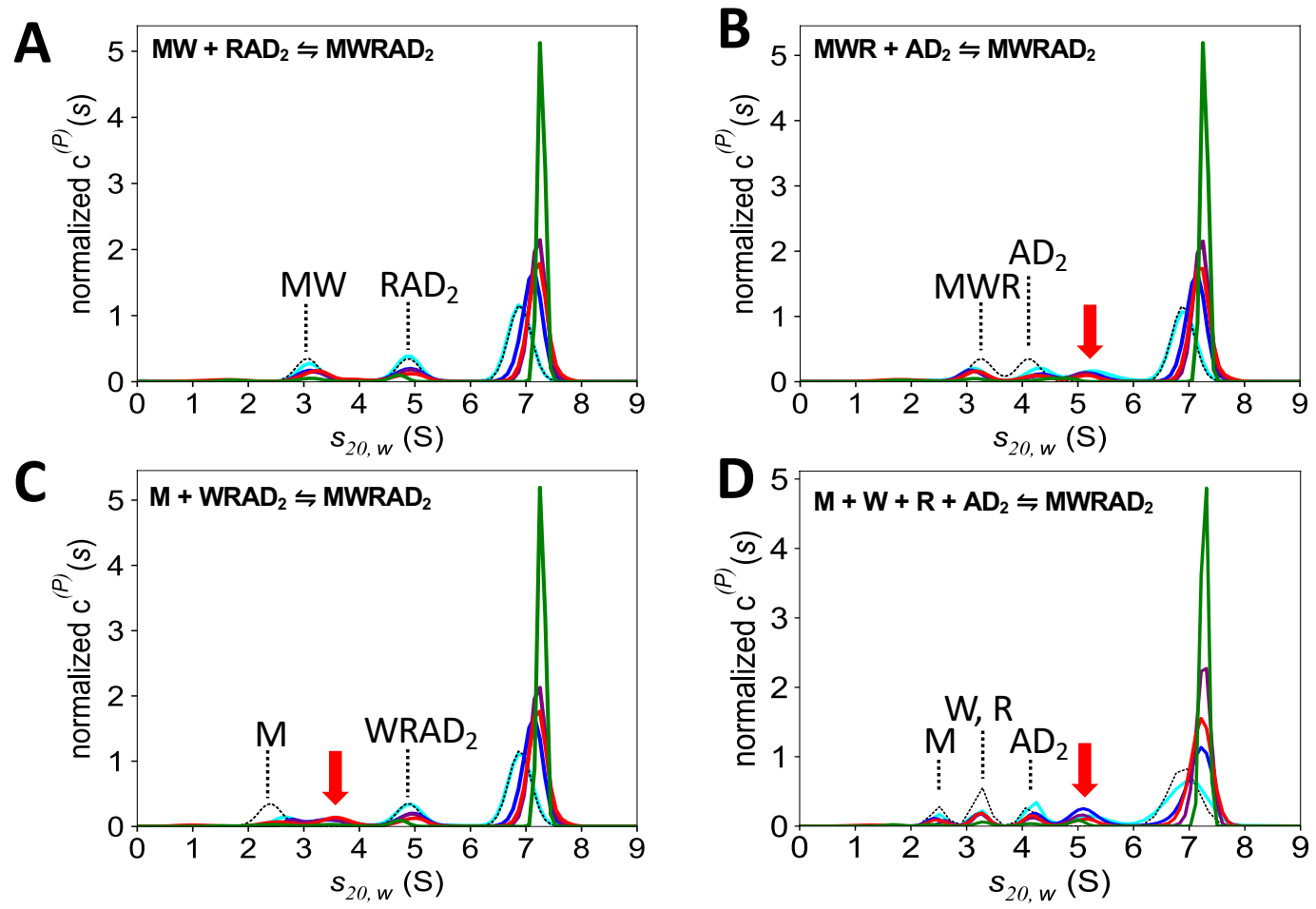

Figure 5: The holo-MLL1 core complex assembles from $M W$ and $R^{2} D_{2}$ subcomplexes. Bayesian analysis of $\mathrm{MWRAD}_{2}$ SV-AUC data collected at $25^{\circ} \mathrm{C}$. $\mathrm{MWRAD}_{2}$ concentrations were $0.25 \mu \mathrm{M}$ (cyan), $0.5 \mu \mathrm{M}$ (blue), $0.75 \mu \mathrm{M}$ (purple), 1.0 $\mu \mathrm{M}$ (red) and $5.0 \mu \mathrm{M}$ (green). Maximum entropy regularizations were restrained with expected values (indicated with the dotted line) for each indicated sub-complex derived from separate experiments (Fig. S1 and Table S2) to give $c^{(P)}(s)$ distributions (colored lines), which were normalized by total integrated area. Concentrations of $\mathrm{MWRAD}_{2}$ in each run were: $0.25 \mu \mathrm{M}$ (cyan), $0.5 \mu \mathrm{M}$ (blue), $0.75 \mu \mathrm{M}$ (purple), $1.0 \mu \mathrm{M}$ (red) and $5.0 \mu \mathrm{M}$ (green). The $C^{(P)}(s)$ distributions used the following $S$ values as prior expectations: (A) MW (3.0 S), RAD 2 (4.4 S), and $\mathrm{MWRAD}_{2}$ (6.9 S) (scheme 1); (B) MWR (3.3 S), $A D_{2}(4.1 \mathrm{~S}$ ), and MWRAD 2 (6.9S) (scheme 2). (C) M (2.3 S), WRAD (4.4 S), and $\mathrm{MWRAD}_{2}$ (6.9S) (scheme 3). (D) M(2.3 S), W(3.2S), R(3.4 S), $A D_{2}(4.1$ $\mathrm{S})$, and $\mathrm{MWRAD}_{2}(6.9 \mathrm{~S})$ (concerted assembly scheme). 
Figure 6 - Namitz, Tan and Cosgrove
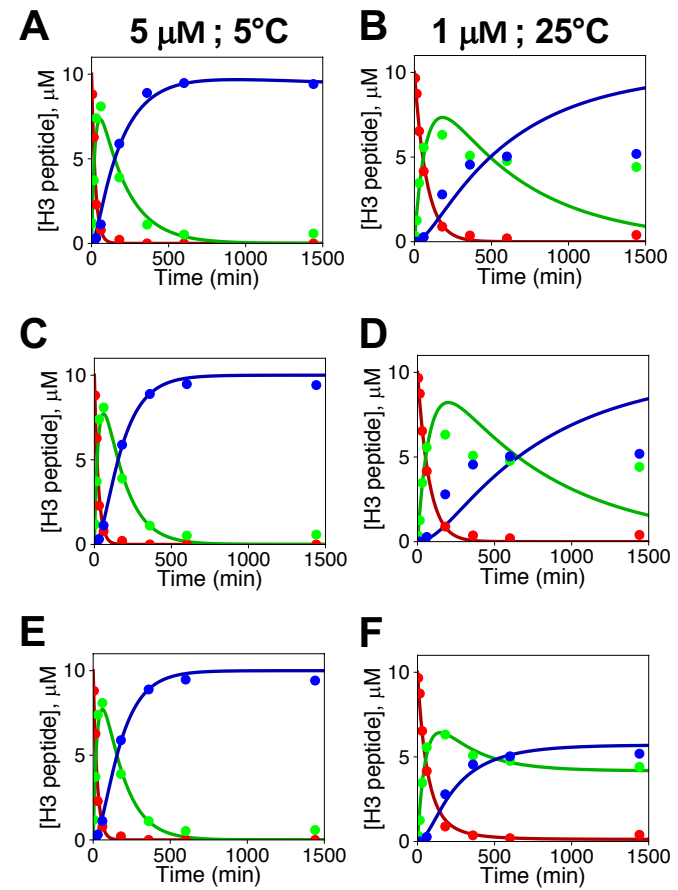

Legend: $\_$me0 $-\mathrm{me} 1-\mathrm{me} 2-\mathrm{me} 3$
Scheme 4:

$$
\mathrm{me} 0 \stackrel{k_{\text {me1 }}}{\longrightarrow} \mathrm{me} 1 \stackrel{k_{\text {me2 }}}{\longrightarrow} \mathrm{me} 2
$$

Scheme 5:

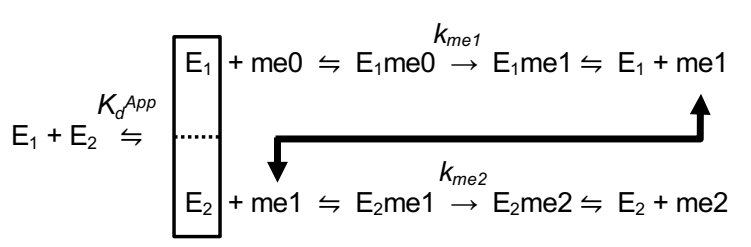

Scheme 6:

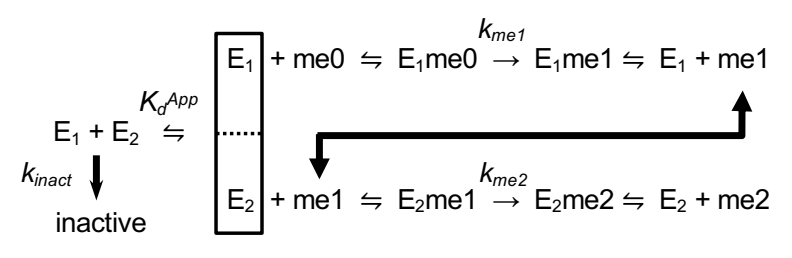

H

$1 \mu \mathrm{M} ; 25^{\circ} \mathrm{C}$
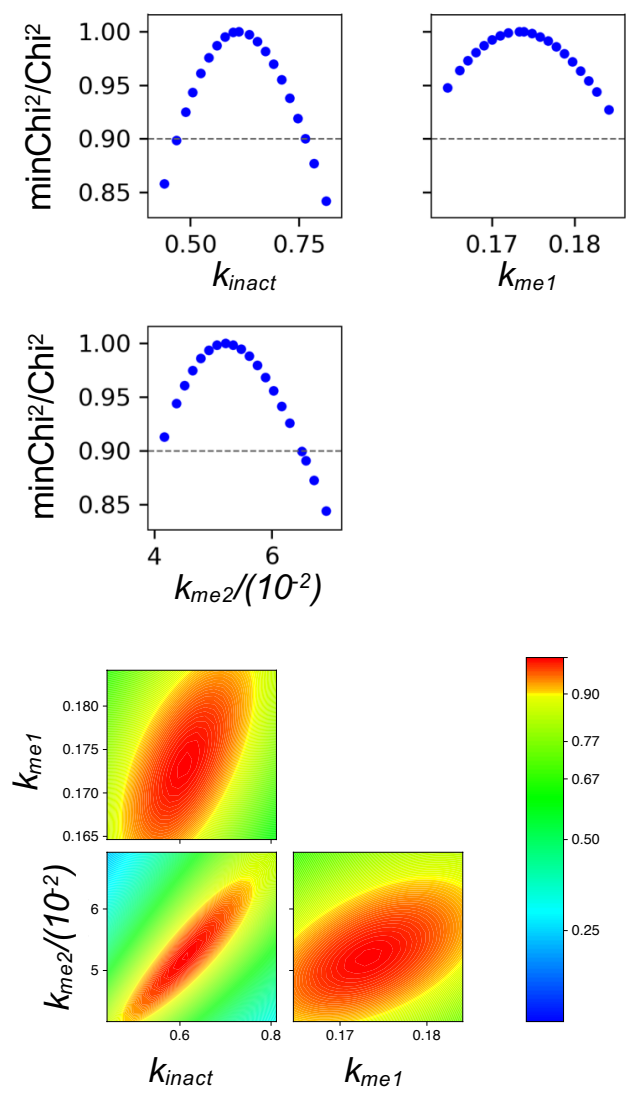

Figure 6: Comparison of minimal reaction pathways. (A, C, E) show the fits (solid lines) for the concentrations of each peptide species (me0, me1, or me2) during the reaction time course catalyzed by $5 \mu M M^{\prime} R_{R A}$ at $5^{\circ} \mathrm{C}$. Each panel shows the fits to the same data using Scheme $4(A)$, Scheme $5(C)$, or Scheme 6 (E). Panels (B, D, F) show fits for Schemes 4-6, respectively, for the reaction time course catalyzed by $1 \mu \mathrm{M} \mathrm{MWRAD}$ at $25^{\circ} \mathrm{C}$. (G) Fitspace confidence contour analysis for the reaction catalyzed by $5 \mu \mathrm{M} \mathrm{MWRAD}$ at $5^{\circ} \mathrm{C}$ fit with Scheme $6 . k_{\text {inact }}$ is not constrained by the data, mainly due to the absence of detectable enzyme inactivation during the reaction time course at $5^{\circ} \mathrm{C} .(\mathrm{H})$ Fit space confidence contour analysis of the fit of Scheme 6 to the reaction catalyzed by $1 \mu \mathrm{MMWRAD}{ }_{2}$ at $25^{\circ} \mathrm{C}$. $k_{\text {inact }}$ is now constrained by the data. 


\section{Figure 7 - Namitz, Tan and Cosgrove}

[MWRAD $]$,

$\underline{\mu M}$

0.25

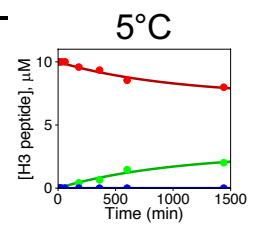

0.50

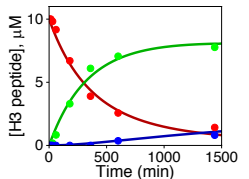

0.75

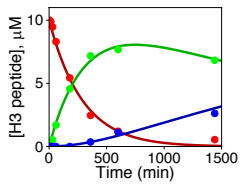

1.00

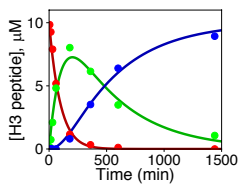

5.00

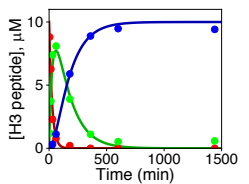

$10^{\circ} \mathrm{C}$
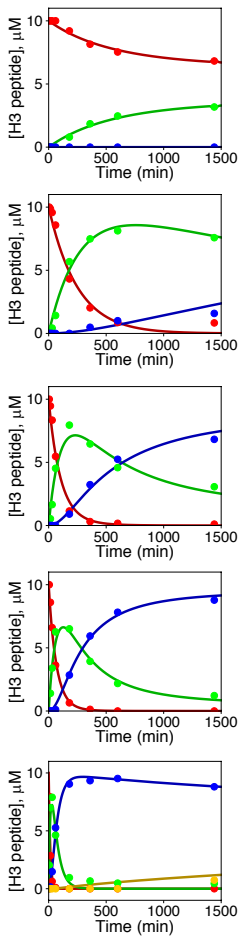
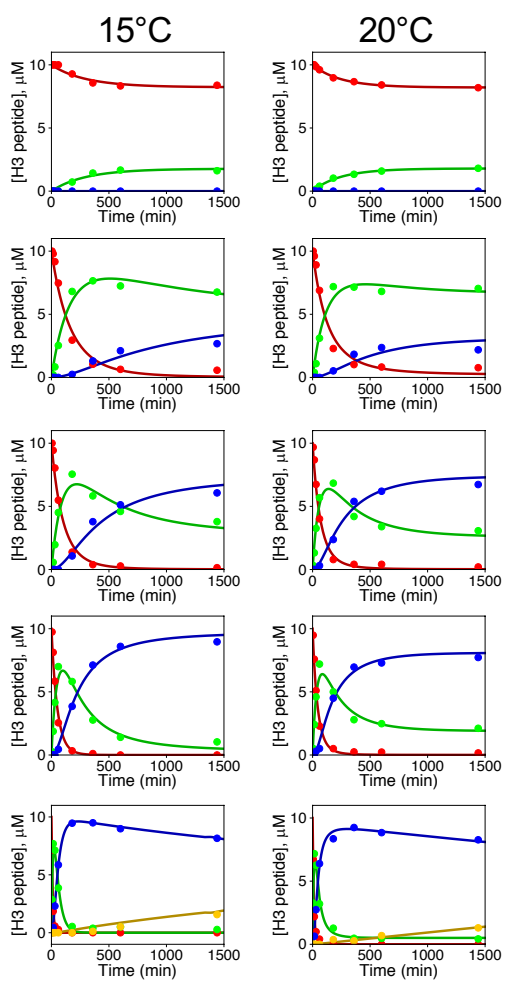
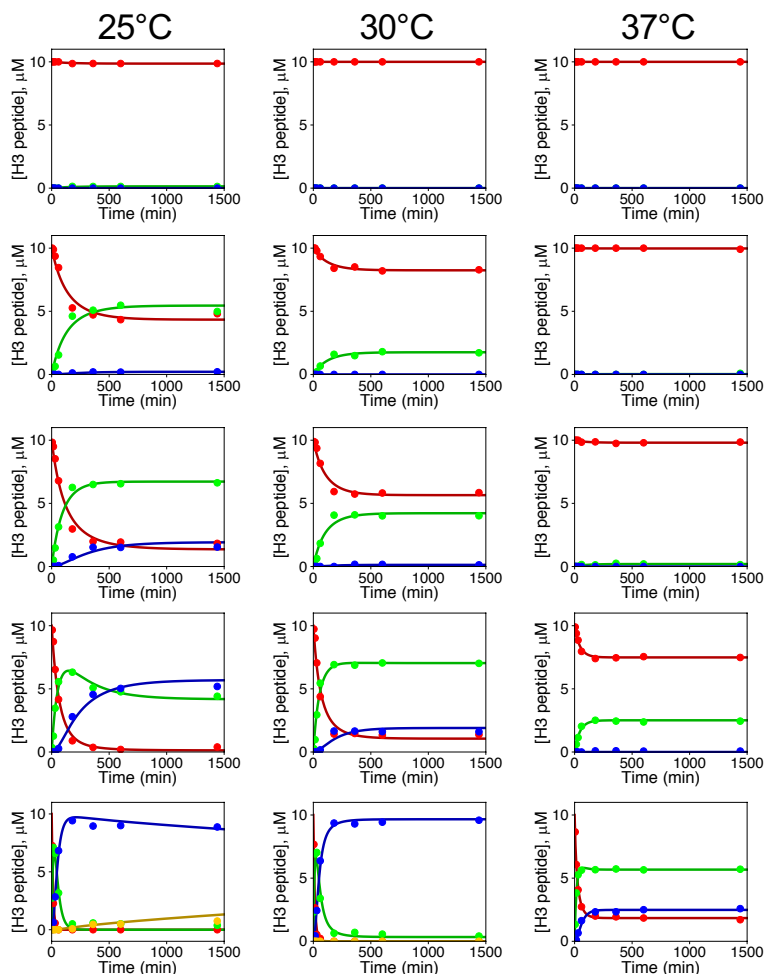
me3

Figure 7: Temperature and concentration dependence of MLL1 core complex enzymatic activity. Time courses for reactions at the indicated $M W R A D_{2}$ concentrations and temperatures were plotted and fit using Scheme 6. Each time point represents the average from two independent experiments. Concentrations of each peptide species were plotted in red for $\mathrm{H} 3 \mathrm{~K} 4 \mathrm{me}$, green for $\mathrm{H} 3 \mathrm{~K} 4 \mathrm{me} 1$, blue for $\mathrm{H} 3 \mathrm{~K} 4 \mathrm{me} 2$. For reactions showing small amounts of $\mathrm{H} 3 \mathrm{~K} 4 \mathrm{me} 3$ (yellow), Scheme 6 was modified to incorporate an additional turnover step followed by product release. 

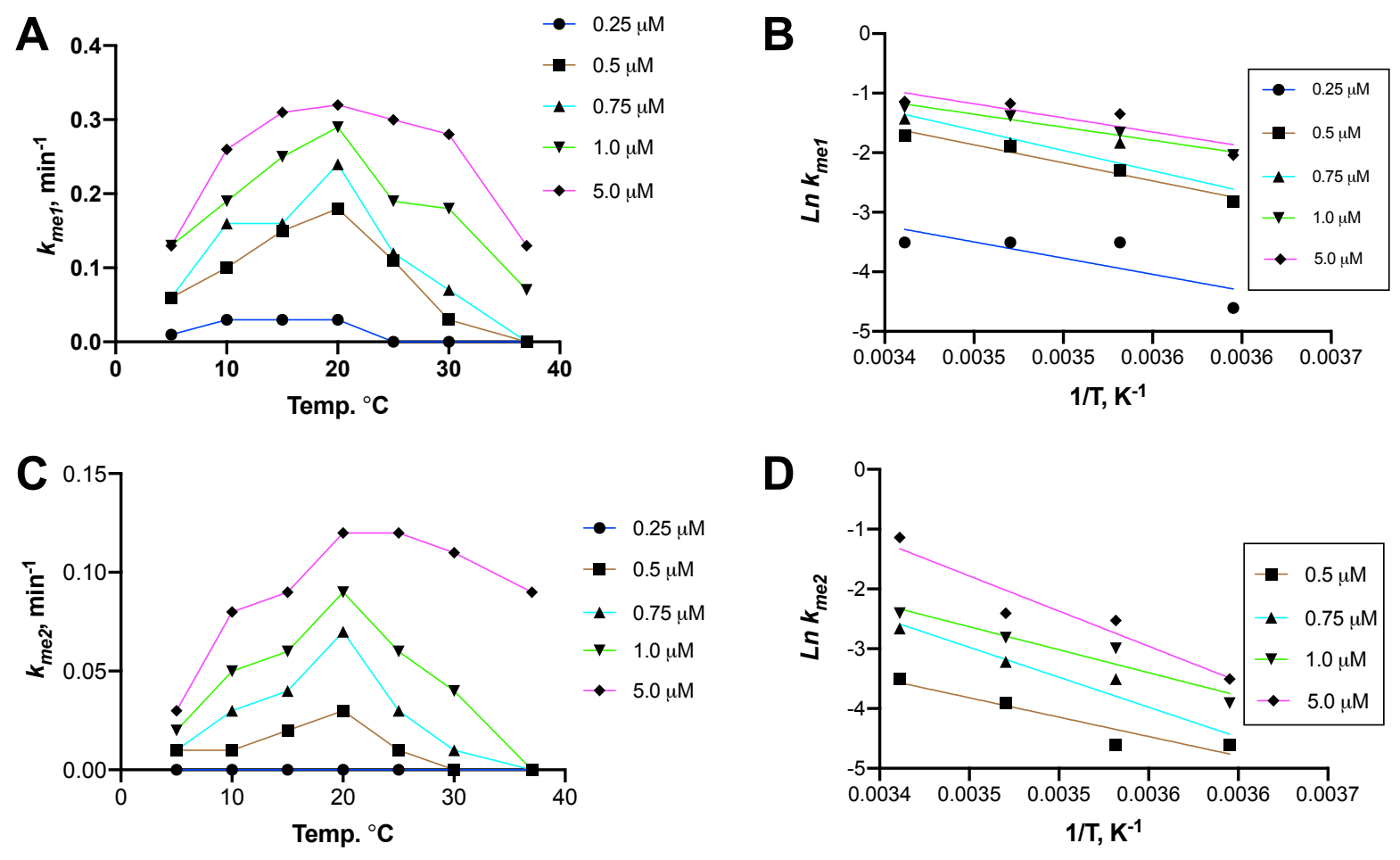

Figure 8: Effect of temperature on $M W R A D_{2}$ enzymatic activity. ( $A$ and $C$ ), rates of $H 3 K 4$ mono- $(A)$ and dimethylation (C) plotted as a function of temperature. Arrhenius behavior (defined as a doubling of the rate for every $10^{\circ} \mathrm{C}$ increase in temperature) was observed between $5^{\circ} \mathrm{C}$ and $20^{\circ} \mathrm{C}$ for most concentrations. (B and $\left.\mathrm{D}\right)$, Arrhenius plots for $\mathrm{H} 3 \mathrm{~K} 4$ mono- $(\mathrm{B})$ and dimethylation (D) for the data collected between $5^{\circ} \mathrm{C}$ and $20^{\circ} \mathrm{C}$. The lines represent linear regression fits to the data collected at the indicated $M W R A D_{2}$ concentrations. $E_{a}$ values were obtained from the slope of the Arrhenius fits, where slope $=-\left(E_{a} / R\right)$ at each enzyme concentration. 
bioRxiv preprint doi: https://doi.org/10.1101/870667; this version posted December 10, 2019. The copyright holder for this preprint (which was not certified by peer review) is the author/funder, who has granted bioRxiv a license to display the preprint in perpetuity. It is made available

A

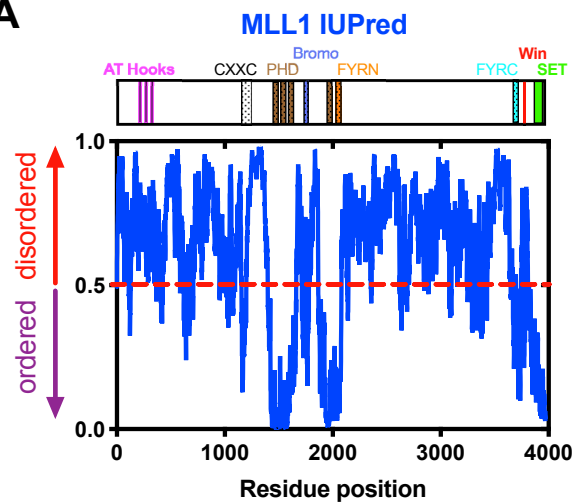

C

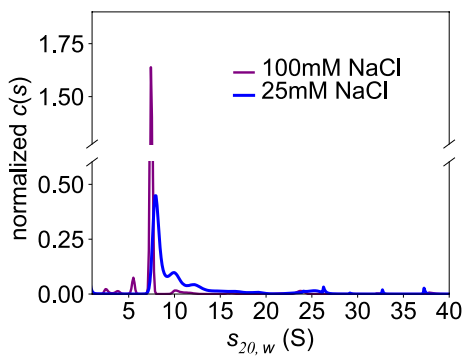

$\mathbf{E}$

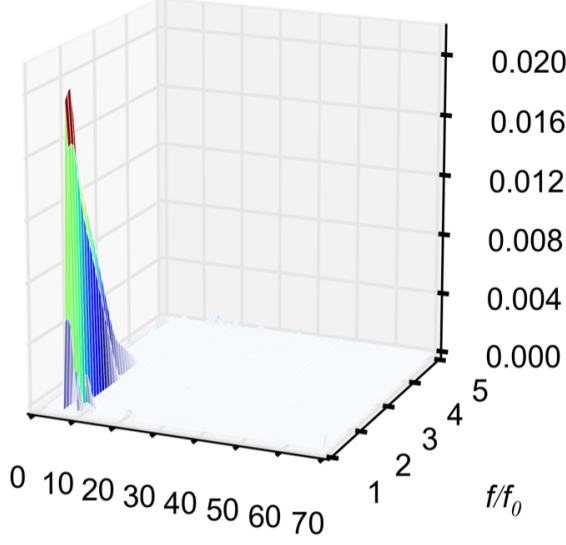

sedimentation coefficient (S)

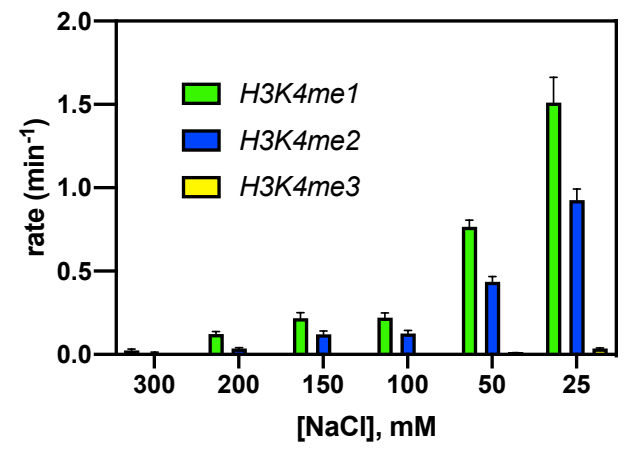

D
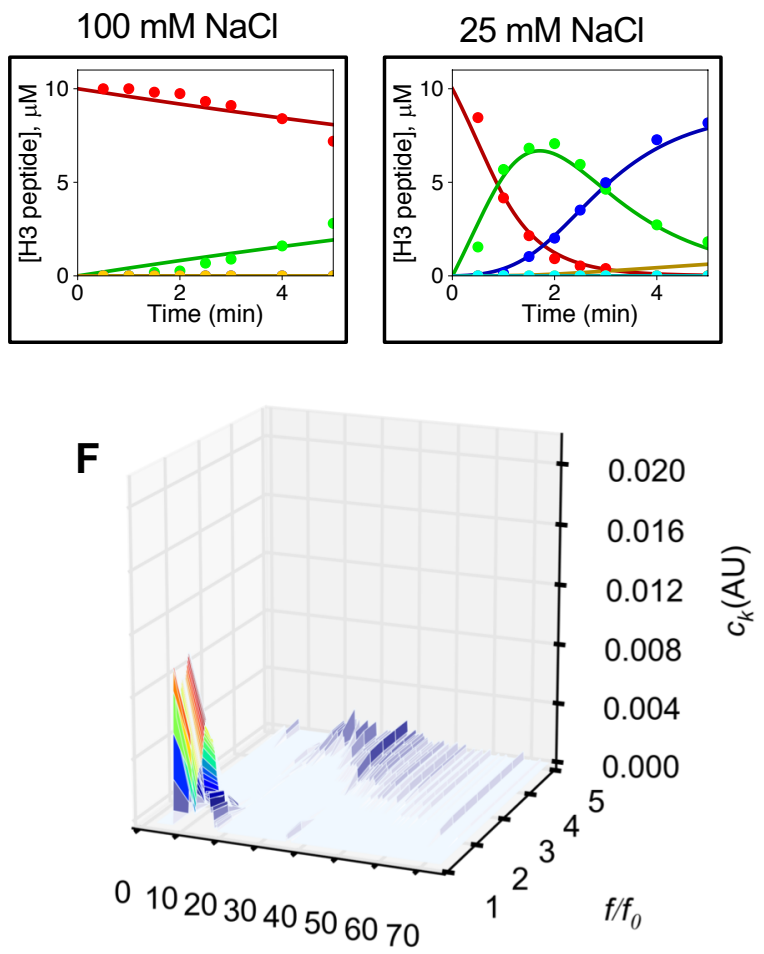

sedimentation coefficient (S)

G

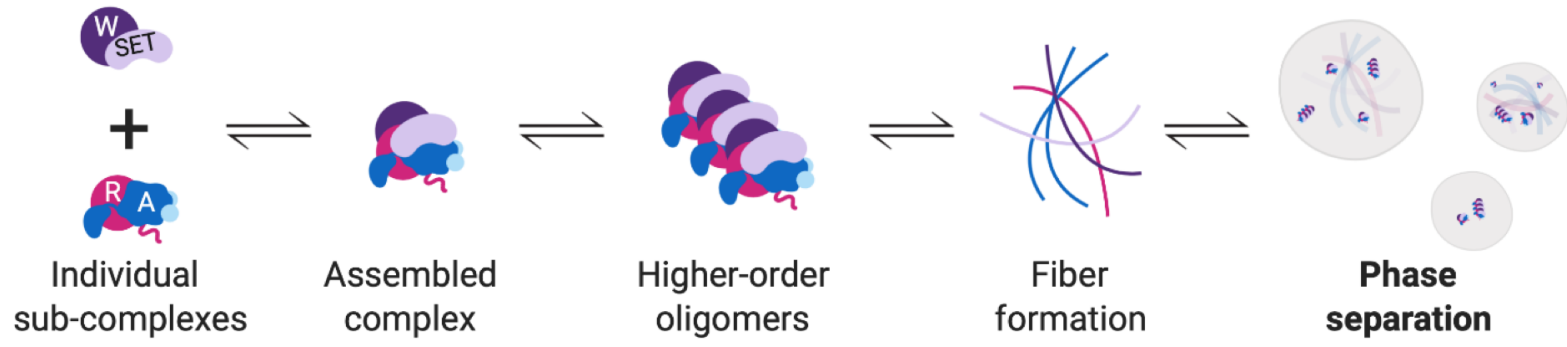

Figure 9: MLL1 core complex enzymatic activity is increased under conditions that induce phase separation. (A) IUPred disorder prediction (71) for the full-length MLL1 protein. Uniprot sub-domain boundaries are shown in the schematic above and are summarized in Table S6. (B) Comparison of $5 \mu \mathrm{M}$ MLL1 core complex enzymatic activity at different ionic strengths at $25^{\circ} \mathrm{C}$. (C) SV-AUC comparison of $5.0 \mu \mathrm{M} \mathrm{MWRAD}_{2} c(\mathrm{~s})$ distributions at $100 \mathrm{mM}$ (purple) and $25 \mathrm{mM}$ (blue) NaCl. (D) Reaction time courses of $5.0 \mu \mathrm{M} \mathrm{MWRAD}$ at $100 \mathrm{mM} \mathrm{NaCl}$ (left panel) and $25 \mathrm{mM} \mathrm{NaCl}$ (right panel) at $25^{\circ} \mathrm{C}$. Each time point represents the mean concentration of each peptide species, and solid lines show the fit using Scheme 6. Peptide species were $\mathrm{H} 3 \mathrm{~K} 4 \mathrm{me} 0$ (red), $\mathrm{H} 3 \mathrm{~K} 4 \mathrm{me} 1$ (green), H3K4me2 (blue), and H3K4me3 (yellow). (E and F) Size and shape analyses (c(s, $\left.f_{r}\right)$ ) from SV-AUC runs of $5.0 \mu \mathrm{M} \mathrm{MWRAD}{ }_{2}$ in buffer with either $100 \mathrm{mM}(\mathrm{E})$ or $25 \mathrm{mM}(\mathrm{F}) \mathrm{NaCl}$, each at $25^{\circ} \mathrm{C}$. (G) A schematic of the build-up of higherorder oligomers and subsequent fiber formation preceding phase separation (Created with BioRender.com). 
A $\quad 100 \mathrm{mM} \mathrm{NaCl}$

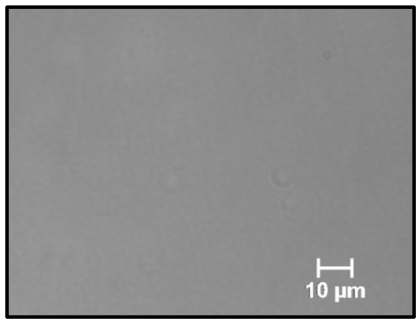

C $\quad+7 \%$ Dextran

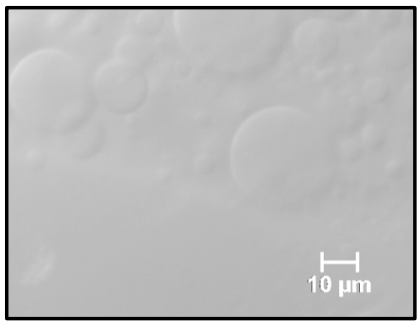

E $\mathrm{M}\left(\mathrm{W}^{*}\right) \mathrm{RAD} \mathrm{D}_{2}$

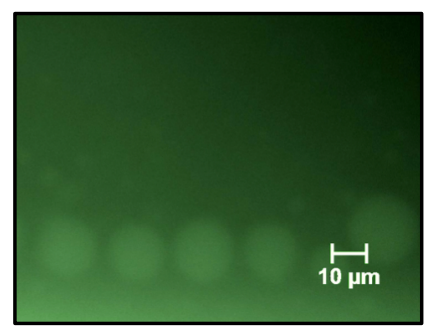

B $\quad 25 \mathrm{mM} \mathrm{NaCl}$

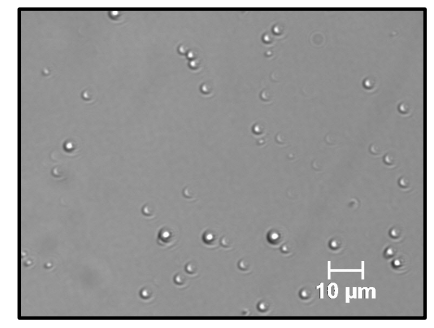

D $+5 \%$ 1, 6-hexanediol

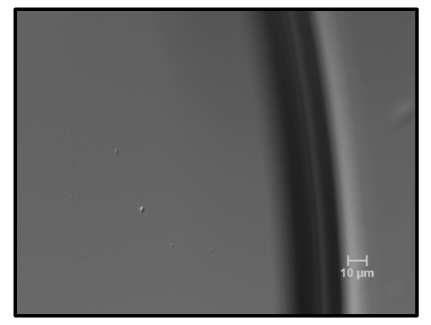

F $\quad \operatorname{MW}\left(R^{*}\right) A D_{2}$

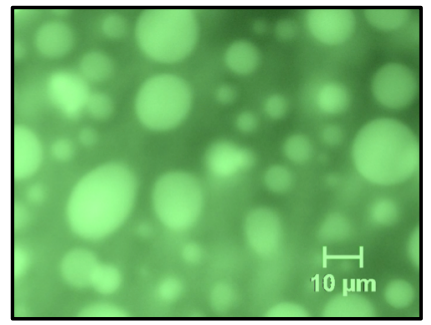

Figure 10: The MLL1 core complex phase separates at a low concentration and physiological ionic strength. $(A, B)$ DIC microscopy images of MLL1 core complex enzymatic reactions at $100 \mathrm{mM}(\mathrm{A})$ or 25 $\mathrm{mM}(\mathrm{B}) \mathrm{NaCl}$. Each reaction contained $5.0 \mu \mathrm{M} \mathrm{MWRAD}{ }_{2}, 100 \mu \mathrm{M} \mathrm{H} 3^{1-20}$ peptide and $250 \mu \mathrm{M}$ AdoMet in reaction buffer at $25^{\circ} \mathrm{C}$. (C) The same as in (B) but with $7 \%$ dextran (see also Supplementary movie S1). (D) Same as in (C) but with 5\% 1,6 hexanediol. (E,F) Fluorescence microscopy images of the MLL1 core complex assembled with AlexaFluor 488-labeled WDR5 (E) or RbBP5 (F) subunits (see also supplementary movies S3 and S4). The conditions were $5.0 \mu \mathrm{M}$ gel filtration-purified complex (see supplementary Fig.S7) in reaction buffer with $10 \mu \mathrm{M} \mathrm{H} 3^{1-20}$ peptide, $250 \mu \mathrm{M}$ AdoMet, and $150 \mathrm{mM} \mathrm{NaCl}$. 


\section{Figure 11 - Namitz, Tan and Cosgrove} under aCC-BY-NC-ND 4.0 International license.

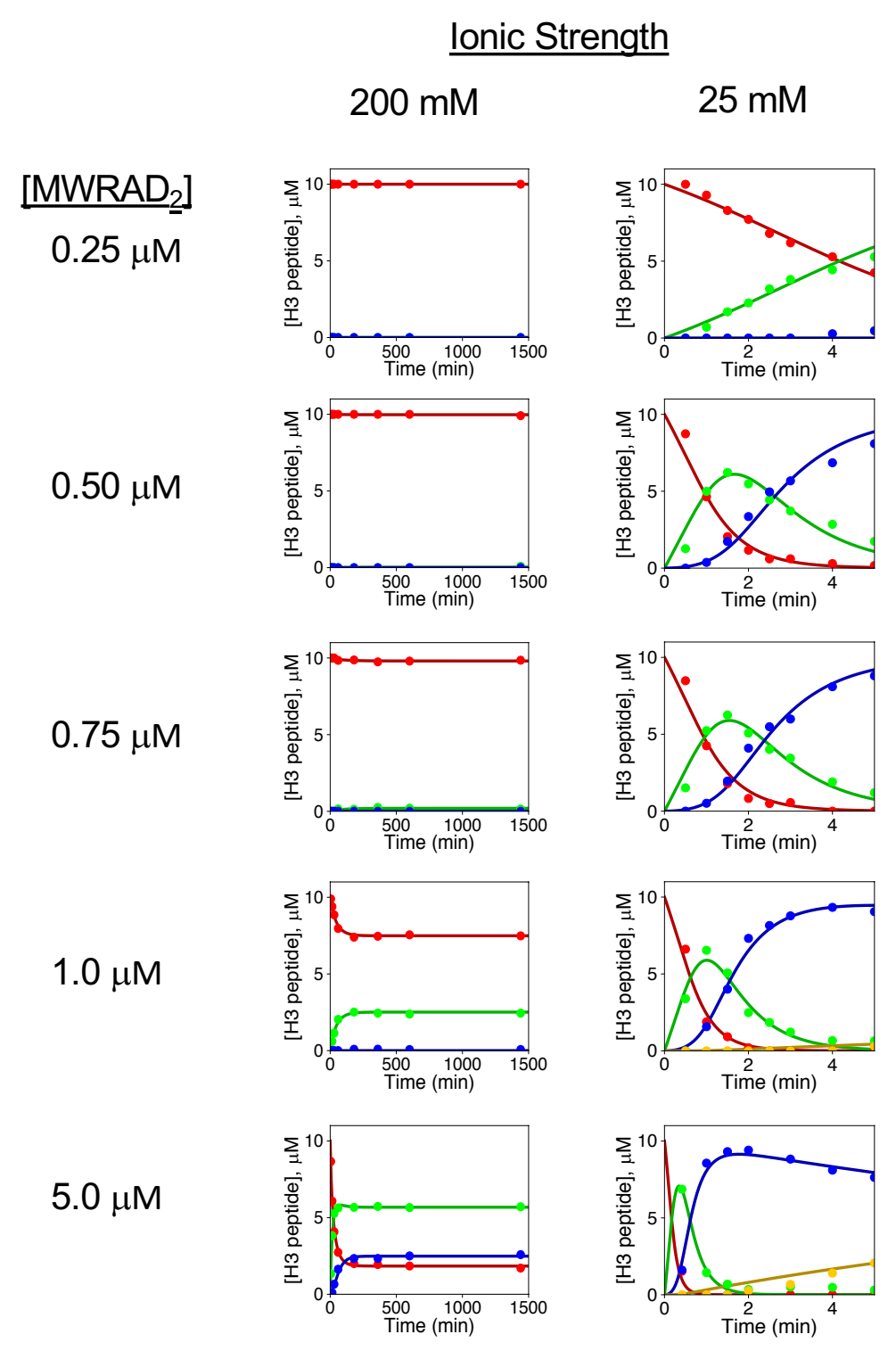

Figure 11: Enzymatic activity of the MLL1 core complex at physiological temperature under phase separation conditions. Comparison of MLL1 core complex enzymatic activity at the indicated concentrations at $37^{\circ} \mathrm{C}$ in high $(200 \mathrm{mM} \mathrm{NaCl})$ vs. low $(25 \mathrm{mM} \mathrm{NaCl})$ ionic strength reaction buffers. The $200 \mathrm{mM} \mathrm{NaCl}$ panels (left) from Fig. 7 are shown again here for the purpose of comparison. Each time point represents the mean concentration of each peptide species and solid lines show the fit using Scheme 6 (Fig.6) or a modified form of Scheme 6 to account for trimethylation. The resulting pseudo-first order rate constants are summarized in Table 5. Peptide species were H3K4me0 (red), H3K4me1 (green), H3K4me2 (blue), and H3K4me3 (yellow). Note the time scale differences required for the high vs. low ionic strength reactions. 


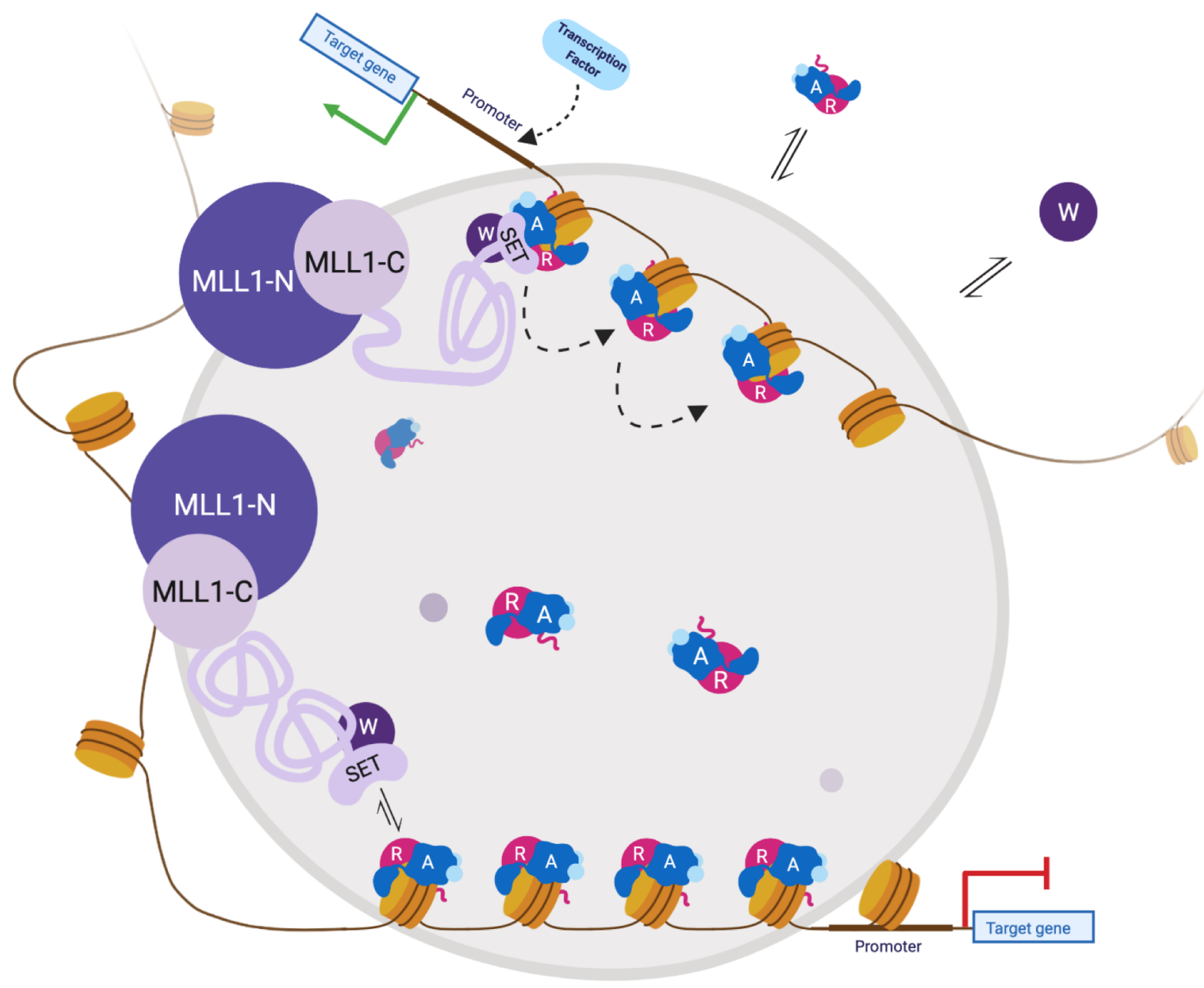

Figure 12: Swinging Domain Model for regulation of MLL1 core complex assembly and enzymatic activity within a transcription factory. MLL1 N-terminal region (MLL1-N) binds to DNA in or near a transcription factory using its DNA and chromatin-recognition domains. The Cterminal region (MLL1-C), which contains the SET domain, binds to WDR5 (W) to create the MW sub-complex, either before or after entry into the factory. The RbBP5, Ash2L, DPY-30 $\left(R^{2} D_{2}\right)$ sub-complex binds nucleosomes. MW then uses a "swinging domain" mechanism within the phase condensate to move the SET domain-WDR5 around the transcription factory, where the high local concentration forces the assembly of the full MLL1 core complex and allows for H3K4 methylation of nucleosomes within the factory that have $\mathrm{RAD}_{2}$ already bound. This can be repeated multiple times within the factory, resulting in extensive H3K4 methylation of nucleosomes that go into the condensate. This methylation results in removal of nucleosomes and recruitment of transcription factors that, in turn, recruit RNA Polymerase II for transcription initiation. Once the chromatin leaves the factory, the reduction in local concentration results in the loss of the RAD sub-complex, as well as a high kinetic barrier to reassembly of $M W R A D_{2}$, preventing any ectopic methylation. This figure was created with BioRender.com 